\title{
Small-bowel capsule endoscopy and device-assisted enteroscopy for diagnosis and treatment of small- bowel disorders: European Society of Gastrointestinal Endoscopy (ESGE) Clinical Guideline

Marco Pennazio ${ }^{1}$, Cristiano Spada ${ }^{2}$, Rami Eliakim ${ }^{3}$, Martin Keuchel ${ }^{4}$, Andrea May ${ }^{5}$, Chris J. Mulder ${ }^{6}$, Emanuele Rondonotti ${ }^{7}$, Samuel N. Adler ${ }^{8}$, Joerg Albert ${ }^{9}$, Peter Baltes ${ }^{4}$, Federico Barbaro ${ }^{2}$, Christophe Cellier ${ }^{10}$, Jean Pierre Charton ${ }^{11}$, Michel Delvaux ${ }^{12}$, Edward J. Despott ${ }^{13}$, Dirk Domagk ${ }^{14}$, Amir Klein ${ }^{15}$, Mark McAlindon ${ }^{16}$, Bruno Rosa ${ }^{17}$, Georgina Rowse $^{18}$, David S. Sanders ${ }^{16}$, Jean Christophe Saurin ${ }^{19}$, Reena Sidhu ${ }^{16}$, Jean-Marc Dumonceau ${ }^{20}$, Cesare Hassan ${ }^{2,21}$, Ian M. Gralnek ${ }^{15}$

Institutions listed at end of article.

Bibliography

DOI http://dx.doi.org/

10.1055/s-0034-1391855

Endoscopy 2015; 47: 352-376

(c) Georg Thieme Verlag KG

Stuttgart · New York

ISSN 0013-726X

\section{Corresponding author}

Marco Pennazio, MD

Division of Gastroenterology

San Giovanni Battista University-

Teaching Hospital,

Via Cavour 31

10123 Turin

Italy

Fax: +39-11-6333979

pennazio.marco@gmail.com

This Guideline is an official statement of the European Society of Gastrointestinal Endoscopy (ESGE). The Guideline was also reviewed and endorsed by the British Society of Gastroenterology (BSG). It addresses the roles of small-bowel capsule endoscopy and device-assisted enteroscopy for diagnosis and treatment of small-bowel disorders.

\section{Main recommendations}

1 ESGE recommends small-bowel video capsule endoscopy as the first-line investigation in patients with obscure gastrointestinal bleeding (strong recommendation, moderate quality evidence).

2 In patients with overt obscure gastrointestinal bleeding, ESGE recommends performing smallbowel capsule endoscopy as soon as possible after the bleeding episode, optimally within 14 days, in order to maximize the diagnostic yield (strong recommendation, moderate quality evidence).

3 ESGE does not recommend the routine performance of second-look endoscopy prior to smallbowel capsule endoscopy; however whether to perform second-look endoscopy before capsule endoscopy in patients with obscure gastrointestinal bleeding or iron-deficiency anaemia should be decided on a case-by-case basis (strong recommendation, low quality evidence).

4 In patients with positive findings at small-bowel capsule endoscopy, ESGE recommends device-assisted enteroscopy to confirm and possibly treat lesions identified by capsule endoscopy (strong recommendation, high quality evidence).

5 ESGE recommends ileocolonoscopy as the first endoscopic examination for investigating patients with suspected Crohn's disease (strong recommendation, high quality evidence).

In patients with suspected Crohn's disease and negative ileocolonoscopy findings, ESGE recommends small-bowel capsule endoscopy as the initial diagnostic modality for investigating the small bowel, in the absence of obstructive symptoms or known stenosis (strong recommendation, moderate quality evidence).
ESGE does not recommend routine small-bowel imaging or the use of the PillCam patency capsule prior to capsule endoscopy in these patients (strong recommendation, low quality evidence). In the presence of obstructive symptoms or known stenosis, ESGE recommends that dedicated small bowel cross-sectional imaging modalities such as magnetic resonance enterography/enteroclysis or computed tomography enterography/enteroclysis should be used first (strong recommendation, low quality evidence).

6 In patients with established Crohn's disease, based on ileocolonoscopy findings, ESGE recommends dedicated cross-sectional imaging for small-bowel evaluation since this has the potential to assess extent and location of any Crohn's disease lesions, to identify strictures, and to assess for extraluminal disease (strong recommendation, low quality evidence).

In patients with unremarkable or nondiagnostic findings from such cross-sectional imaging of the small bowel, ESGE recommends small-bowel capsule endoscopy as a subsequent investigation, if deemed to influence patient management (strong recommendation, low quality evidence). When capsule endoscopy is indicated, ESGE recommends use of the PillCam patency capsule to confirm functional patency of the small bowel (strong recommendation, low quality evidence).

7 ESGE strongly recommends against the use of small-bowel capsule endoscopy for suspected coeliac disease but suggests that capsule endoscopy could be used in patients unwilling or unable to undergo conventional endoscopy (strong recommendation, low quality evidence). 


\section{Abbreviations \\ $\nabla$}

BSG British Society of Gastroenterology

CECDAI Capsule Endoscopy Crohn's Disease Activity Index

CECT contrast-enhanced computed tomography

CI confidence interval

CT computed tomography

CTA computed tomography-angiography

CTE computed tomography-enterography/enteroclysis

DBE double-balloon enteroscopy

EATL enteropathy associated T-cell lymphoma

EMA endomysial antibodies

FAP familial adenomatous polyposis

FOBT faecal occult blood test

GRADE Grading of Recommendations Assessment, Development and Evaluation

GIST gastrointestinal stromal tumour

HLA human leukocyte antigen

IBD inflammatory bowel disease

IBDU inflammatory bowel disease-unclassified

ICCE International Conference on Capsule Endoscopy

IDA iron-deficiency anaemia

MRE magnetic resonance enterography/enteroclysis

MRI magnetic resonance imaging

NPV negative predictive value

NSAIDs nonsteroidal anti-inflammatory drugs

OGD oesophagogastroduodenoscopy

OGIB obscure gastrointestinal bleeding

OR odds ratio

PJS Peutz-Jeghers syndrome

PPV positive predictive value

RCD refractory coeliac disease

RCT randomized controlled trial

SBE single-balloon enteroscopy

SBFT small-bowel follow-through

tTG tissue transglutaminase

VCE (small-bowel) video capsule endoscopy

\section{Introduction}

$\nabla$

The field of gastrointestinal endoscopy has made great strides over the past several decades, and endoscopists have mastered the art of advancing flexible video endoscopes in the upper and lower parts of the gastrointestinal tract. Endoscopic evaluation of the small bowel (i.e., enteroscopy), on the other hand, poses a unique challenge that has plagued physicians for decades. With the development of newer enteroscopic modalities, a more thorough evaluation is now possible. These new techniques comprise small-bowel video capsule endoscopy (VCE) and device-assisted enteroscopy; the latter includes double-balloon enteroscopy (DBE), single-balloon enteroscopy (SBE), spiral enteroscopy, and balloon-guided endoscopy (see Box 1).

VCE has revolutionized small-bowel imaging by providing a reliable and noninvasive method for complete visualization and assessment of the mucosal surface. Given the increased detection of small-bowel disease by VCE, innovations in device-assisted enteroscopy have been crucial for histopathological confirmation, enabling endoscopic therapy in selected cases and thus avoiding the need for surgery. With these recent technological advances, enteroscopy currently has a pivotal role in the evaluation of patients with suspected small-bowel diseases, including obscure gastrointestinal bleeding (OGIB), iron-deficiency anaemia, suspected and known Crohn's disease, tumours, polyposis syndromes, and coeliac disease.

This Guideline, commissioned by the European Society of Gastrointestinal Endoscopy (ESGE) and endorsed by the British Society of Gastroenterology (BSG), in addition to updating previous ESGE guidelines [1,2], analyzes in detail the performance of VCE and device-assisted enteroscopy compared with nonendoscopic methods for the investigation of the small bowel. The aim of this evidence-based and consensus-based Guideline, is to provide caregivers with a comprehensive guide for the clinical application of enteroscopy.

\section{Methods}

$\nabla$

The ESGE commissioned this Guideline and appointed a guideline leader (M.P.) who invited the listed authors to participate in the project development. The key questions were prepared by the coordinating team (M.P. and C.S.) and then approved by the other members. The coordinating team formed task force subgroups, each with its own coordinator, and divided the key topics amongst these task forces (see Appendix e1, available online).

Each task force performed a systematic literature search to prepare evidence-based and well-balanced statements on their assigned key questions. The coordinating team independently performed systematic literature searches with the assistance of a librarian. The Medline, EMBASE and Trip databases were searched including at minimum the following key words: video capsule endoscopy (VCE), double-balloon enteroscopy (DBE), single-balloon endoscopy (SBE), spiral enteroscopy, small-bowel, and enteroscopy. All articles on the use of VCE and device-assisted enteroscopy in patients with OGIB, iron-deficiency anaemia, Crohn's disease, small-bowel tumours, polyposis syndromes, and coeliac disease were selected by title or abstract. All selected articles were graded by the level of evidence and strength of recommendation according to the Grading of Recommendations Assessment, Development and Evaluation (GRADE) system [3,4]. Evidence tables and Recommendations for assessment of guideline implementation are provided in Appendices e2 and e3 (available online).

Each task force proposed statements on their assigned key questions which were discussed and voted on during the plenary meeting held in November 2013. The literature searches were updated through to November 2014. In November 2014, a draft prepared by the coordinating team was sent to all group members. After agreement on a final version, the manuscript was submitted to Endoscopy for publication. The journal subjected the manuscript to peer review and the manuscript was amended to take into account the reviewers' comments. All authors agreed on the final revised manuscript. The final revised manuscript was then reviewed and approved by the BSG. This Guideline was issued in 2015 and will be considered for review and update in 2019 or sooner if new relevant evidence becomes available. Any updates to the Guideline in the interim will be noted on the ESGE website: http://www.esge.com/esge-guidelines.html. 


\section{Box 1 Types of small-bowel endoscopy}

\section{Small-bowel video capsule endoscopy}

Small-bowel video capsule endoscopy (VCE) is a method of endoluminal examination of the small bowel using a wireless disposable capsule-shaped tool which is swallowed and then propelled by gut motility through the gastrointestinal tract. From there it transmits images wirelessly to a data recorder worn by the patient. The types of VCE on the market vary according to manufacturer. The VCE system (PillCam, Covidien plc, Dublin, Ireland; Endocapsule, Olympus Optical Co, Tokyo, Japan; MiroCam, IntroMedic, Seoul, Korea; OMOM capsule, Jinshan Science and Technology Group, Chongqing, China) consists of three main components: a capsule endoscope; a sensing system with a data recorder, and a personal computer workstation with proprietary software for image review and interpretation. All these systems allow real-time review of images during VCE examinations. The CapsoCam (CapsoVision, Cupertino, California, USA) stores all images on a microchip and is designed to offer a $360^{\circ}$ panoramic view with wire-free technology. This capsule system has no data transmission so that patients have to collect the capsule after expulsion in the stool and then send it back to the gastroenterology unit.

\section{Push-enteroscopy}

Push-enteroscopy is a transoral endoluminal examination of the proximal jejunum using a long, flexible endoscope. It is most frequently performed with dedicated push-enteroscopes. Push-enteroscopy does not enable visualization of distal portions of the small intestine but permits tissue sampling and endoscopic treatments of the proximal jejunum. In recent years, device-assisted enteroscopy (DAE) has largely replaced pushenteroscopy, enabling diagnostic and therapeutic procedures throughout the entire length of the small bowel.

\section{Device-assisted enteroscopy}

Device-assisted enteroscopy (DAE) is a generic term for endoluminal examination of the small bowel by any endoscopic technique that includes assisted progression, i.e. with a balloon, overtube, or other stiffening device. DAE includes double-balloon enteroscopy (DBE), single-balloon enteroscopy (SBE), spiral enteroscopy, and balloon-guided endoscopy. In contrast to VCE, DAE is labour-intensive and more invasive but allows real-timecontrolled observation with the option of tissue sampling and endoscopic treatment. DAE therapeutic options cover the whole range of widely used upper endoscopy and colonoscopy interventions.

\section{Double-balloon enteroscopy}

The DBE system (Fujinon Inc., Saitama, Japan) allows deep intubation of the small bowel by pleating the bowel onto a long, flexible enteroscope fitted with a specialized overtube. The enteroscope and the accompanying overtube have latex balloons at their distal end, which can be inflated and deflated with air from a pressure-controlled pump system. By alternating inflation and deflation of these two balloons, combined with instrument insertion and retraction, large portions of the small bowel can be pleated on the overtube using the so-called "push and pull" technique. Complete small-bowel visualization may generally be accomplished by a combined approach via the antegrade (oral) and retrograde (anal) route.

\section{Single-balloon enteroscopy}

The SBE system (Olympus Optical Co, Tokyo, Japan) uses only one latex-free balloon, which is attached to the distal end of the overtube. In contrast to the DBE device, there is no balloon attached at the enteroscope, and therefore a stable position of the device has to be maintained by a combination of endoscope tip angulation and suctioning into the small-bowel wall. The same "push and pull" technique as applied with the DBE system is used to pleat the small bowel onto the overtube, and to inspect on withdrawal.

\section{Spiral enteroscopy}

In spiral enteroscopy (Spirus Medical LLC, West Bridgewater, Massachusetts, USA), an enteroscope is passed through a disposable specialized overtube that has a spiral raised element at its distal end, which aids in the advancement of the enteroscope through the small bowel. The enteroscope can be locked in the overtube allowing the option of spiralling the overtube and enteroscope into the small bowel using clockwise rotation. Alternatively, the overtube can be unlocked, allowing the endoscope to be advanced into the small bowel through the overtube. Withdrawal is achieved by pulling the endoscope back to the $140-\mathrm{cm}$ mark, and then gently rotating counterclockwise to draw back the scope.

Balloon-guided endoscopy

The NaviAid AB device (SMART Medical Systems Ltd., Ra'anana, Israel) is an on-demand balloon catheter that is inserted through the 3.7-mm working channel of a standard colonoscope and enables it to advance deep into the small bowel in either an antegrade or retrograde approach. It consists of a balloon inflation/deflation system and a single-use latex-free balloon catheter, designed for anchoring in the small bowel. The balloon is inflated to anchor in the intestine and a repetitive push-pull technique is performed, with the endoscope sliding over the guiding catheter to the balloon inflated in the distal small bowel. The catheter may be removed to allow for therapeutic intervention while maintaining scope position. The balloon catheter can then be reinserted for further advancement.

Intraoperative enteroscopy

Intraoperative enteroscopy is an exploration of the small bowel with a flexible endoscope during a surgical procedure. The endoscope can be introduced either orally or via an enterotomy. The progression of the endoscope through the small intestine is facilitated by the manual external assistance of the surgeon.

\section{Recommendations and statements}

\section{$\nabla$}

Evidence statements and recommendations are shown with a green background; main recommendations are in bold. 


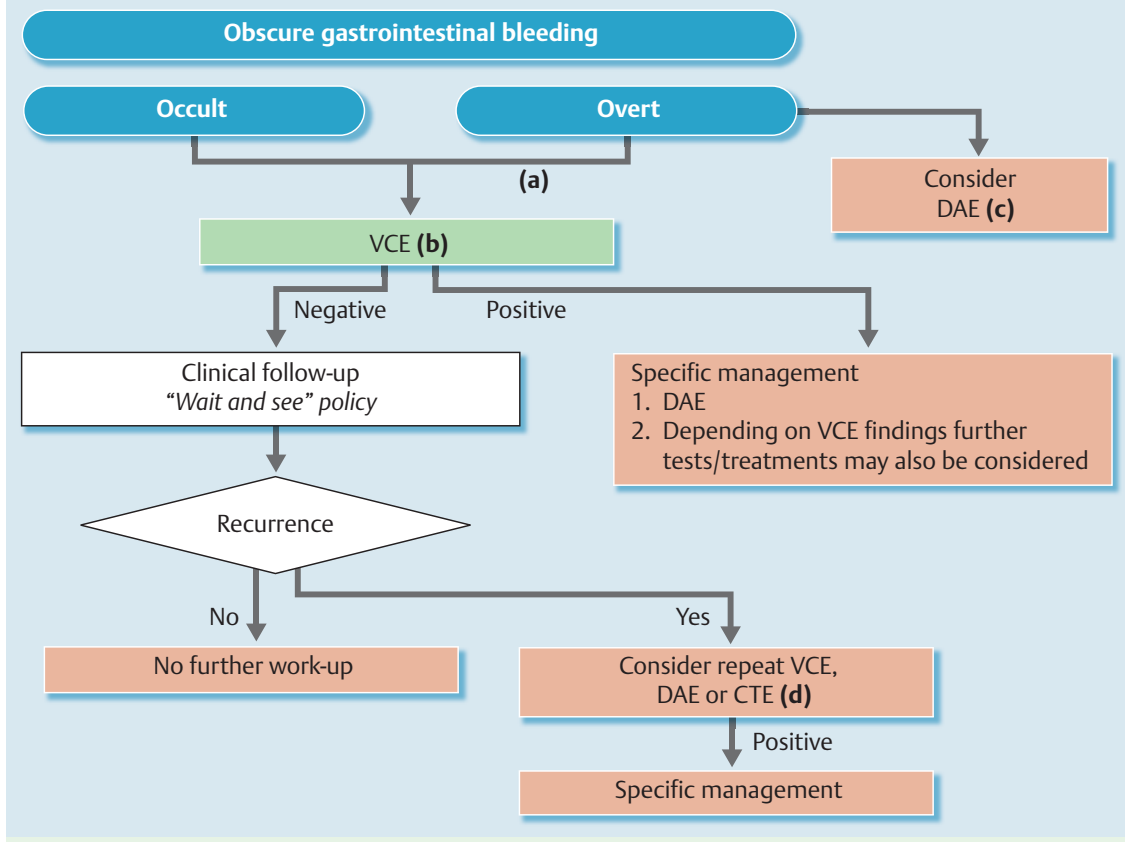

Fig. 1 Recommended approaches for diagnosis and treatment of obscure gastrointestinal bleeding. (a) In patients with overt obscure gastrointestinal bleeding (OGIB), small-bowel video capsule endoscopy (VCE) should be performed as soon as possible after the bleeding episode, optimally within 14 days.

(b) When VCE is contraindicated or unavailable, device-assisted endoscopy (DAE) may be the preferred initial test for small-bowel evaluation.

(c) In patients with significant active bleeding and unsuitable for flexible endoscopy, computed tomography (CT)-angiography or angiography may also be considered.

(d) Upper and/or lower gastrointestinal endoscopy may also be considered on a case-by-case basis to identify lesions overlooked at the initial endoscopy. CTE, computed tomography enterography/enteroclysis.

\section{Obscure gastrointestinal bleeding}

\section{ESGE recommends small-bowel video capsule endoscopy as the first-line investigation in patients with obscure gastroin- testinal bleeding (strong recommendation, moderate quality evidence).}

Obscure gastrointestinal bleeding (OGIB) accounts for approximately $5 \%$ of all cases of gastrointestinal bleeding and is usually due to a lesion in the small bowel. There are few studies evaluating accuracy parameters (sensitivity, specificity, positive predictive value [PPV], negative predictive value [NPV], likelihood ratios) for small-bowel video capsule endoscopy (VCE) in occult and overt OGIB. However, the presently available evidence on the diagnostic usefulness of VCE is sufficient to support the use of VCE for OGIB $[5,6]$.

The accuracy parameters for VCE are uncertain because there is no standard comparative method; this in turn is related to the lack of a reliable criterion standard. In this context, the ideal criterion standard would be intraoperative enteroscopy, but the latter is associated with significant mortality and morbidity ( $5 \%$ and $17 \%$, respectively) and it cannot be routinely recommended for diagnostic purposes in patients with OGIB [7]. For OGIB, there is only one trial that compares VCE and intraoperative enteroscopy and reports accuracy parameters (VCE sensitivity $95 \%$, specificity 75\%) [8]; there are a few studies comparing VCE with complete small-bowel exploration by device-assisted enteroscopy, and there is one trial that uses a combined criterion standard (including results of other procedures and/or outcomes during followup) [9-11]. For all these reasons, the diagnostic yield (i.e., the detection rate for what are thought to be clinically significant findings) is typically reported in small-bowel studies, as a proxy estimate of the diagnostic capability of VCE. There are limited data regarding differentiation of OGIB into occult vs. overt subtypes and thus the diagnostic yield for VCE in OGIB is generally reported as an overall value.

In a recently published updated meta-analysis [12], the reported pooled diagnostic yield for VCE was $61.7 \%$ (95\%CI 47.3 - 76.1). Si- milarly, in a large systematic review, Liao et al. reported a "detection rate" for VCE in OGIB of $60.5 \%$ (95\%CI 57.2-63.9) [13]. Earlier meta-analyses reported similar overall diagnostic yields for VCE in OGIB patients [14-16].

Several studies evaluating the diagnostic yields of the various methods for investigating the small bowel show that they are lower than that of VCE. Such studies are mostly retrospective and characterized by multiple bias. For this reason, we have based our assessment only on studies that directly compare VCE with other methods. Such comparisons are discussed in detail in the following paragraphs. Among the different methods considered, only device-assisted enteroscopy showed similar performances to that of VCE (see below); however, compared with VCE, device-assisted enteroscopy has a lower rate of complete examination of the small-bowel and is highly invasive. For these reasons it seems reasonable to recommend VCE as the first-line investigation in patients with OGIB (see $\bullet$ Fig. 1).

A number of clinical factors have been reported to be associated with a higher diagnostic yield at VCE in patients with OGIB. Pennazio et al. [10] reported that the highest VCE yield was in patients with active bleeding (92.3\%) or occult bleeding (44.2\%), whereas patients with previous overt bleeding had the lowest yield $(12.9 \%)$. A larger and more recent study confirmed that overt bleeding is the factor most strongly associated with a definitive diagnosis by VCE in OGIB [17]. Greater age, use of warfarin, and liver co-morbidity also seem to be related to a higher VCE yield $[18,19]$. A multivariate analysis also showed that factors significantly associated with positive findings at VCE included a higher number of oesophagogastroduodenoscopies (OGDs) performed prior to VCE (odds ratio [OR] 1.17, 95\%CI 1.00-1.37), increasing transfusion requirements (3-9 units, OR $1.70,95 \% \mathrm{Cl}$ $1.08-2.66$; and $\geq 10$ units, OR 2.72, 95\%CI 1.69-4.37), and connective tissue disease (OR 2.24, 95\%CI 1.14-4.41) (all $P<0.045$ ) [20].

In patients with OGIB, VCE showed an excellent safety profile: Liao et al. [13] reported a overall pooled retention rate of $1.4 \%$ (95\%CI $1.2 \%-1.6 \%)$ and a retention rate of $1.2 \%(95 \% \mathrm{CI} 0.9 \%$ $1.6 \%$ in patients with OGIB. Thus routine small-bowel imaging 
or the use of the PillCam patency capsule (Covidien, Dublin, Ireland) is not essential prior to VCE in these patients.

\section{In patients with overt obscure gastrointestinal bleeding ESGE recommends performing small-bowel capsule endoscopy as soon as possible after the bleeding episode, optimally within 14 days, in order to maximize the diagnostic yield (strong re- commendation, moderate quality evidence).}

Early performance of VCE appears to be an important factor, associated with significantly higher diagnostic yield compared with delayed VCE. There are no prospective studies addressing the relationship between timing of VCE and diagnostic yield. However, several retrospective studies, evaluating clinical outcome of patients with OGIB, have shown that earlier VCE contributes to higher diagnostic yield compared with delayed VCE. Two studies $[10,18]$ addressing the higher yield of VCE with overt versus occult OGIB, also demonstrated that shorter intervals between the bleeding episode and performance of VCE increased the diagnostic yield, especially of clinically significant lesions.

Katsinelos et al. [21] evaluated, whether timing of VCE, influences diagnostic yield. In their study, in patients with overt bleeding, the diagnostic yield was 14/16 (87.5\%) in those who underwent VCE during the first 10 days following the bleeding episode, while it was only $1 / 9(11.1 \%)$ for those who had VCE more than 10 days afterwards. Similar results were obtained by Bresci et al. [22] who demonstrated a positive yield of $92 \%$ when VCE was performed within 15 days after diagnosis of OGIB, compared with only $34 \%$ for VCE more than 15 days after diagnosis. This hypothesis has recently been confirmed in a group of 144 patients with overt OGIB, in whom early use of VCE within 3 days of hospital admission resulted in a significantly higher diagnostic yield [23].

In patients with occult OGIB it is often difficult to determine the actual length of the clinical history and there are no data that show a clear impact of timing of VCE on diagnostic yield.

ESGE recommends against push-enteroscopy as the first-line investigation in patients with obscure gastrointestinal bleeding, because of its lower diagnostic yield compared with small-bowel capsule endoscopy (strong recommendation, moderate quality evidence).

Because of capsule endoscopy's excellent safety profile, patient tolerability, and potential for complete enteroscopy, ESGE recommends performance of small-bowel capsule endoscopy as the first-line examination, before consideration of device-assisted enteroscopy, when small-bowel evaluation is indicated for obscure gastrointestinal bleeding (strong recommendation, moderate quality evidence).

Compared with alternative modalities, VCE has been shown to be significantly superior to push-enteroscopy and both conventional and cross-sectional radiology, and to be as good as device-assisted enteroscopy in evaluating and finding the lesion(s) causing the bleeding. When VCE and push-enteroscopy were compared for the evaluation of OGIB, the diagnostic yield of VCE for "clinically significant findings" was $56 \%$ for VCE versus $26 \%$ for push-enteroscopy (incremental yield 30\%, 95\%CI 21\%-38\%, P<0.001\%)
$[14,24]$. However, the studies used to populate these meta-analyses have several limitations, such as the absence of a gold standard modality and subjective criteria for positive findings at VCE. There is only a single cross-over randomized controlled trial on this topic [25]. In that study, a definitive source of bleeding was identified in more patients in the VCE group than in the push-enteroscopy group (overall 50\% vs. $24 \%$; small-bowel-only $43 \%$ vs. $11 \%)$. Fewer lesions were missed by VCE than by push-enteroscopy. VCE missed no lesions in the small bowel, whereas all lesions missed lesions by push-enteroscopy were located in the small bowel. Patients who started with VCE were less likely to require the second investigation than were patients who initially underwent push-enteroscopy.

There has been no randomized controlled trial comparing the efficacy of VCE and double-balloon enteroscopy (DBE) in OGIB. However four meta-analyses comparing VCE and DBE have been published; comparison of the overall diagnostic yield between the two modalities gave the same result in all four meta-analyses $[12,15,16,26]$. In detail, when the diagnostic yield of VCE was compared with that of double-balloon enteroscopy in OGIB, the pooled diagnostic yield for VCE was $61.7 \%$ (95\%CI 47.3-76.1) and for DBE it was 55.5\% (95\%CI 48.9-62.1) [12]. Compared with device-assisted enteroscopy, VCE has, however, a higher rate of complete enteroscopy and a lower rate of complications and it is less invasive. Although the clinical presentation may indicate the preferential endoscopic insertion route for deviceassisted enteroscopy, VCE is also an effective tool for guiding the selection of the correct approach (oral vs. anal). The time point during transit of the capsule at which VCE identifies the lesion should guide the choice of the insertion route, even though different time thresholds have been proposed $[27,28]$.

ESGE recommends performance of small-bowel capsule endoscopy as the first-line examination, before consideration of smallbowel radiographic studies or mesenteric angiography, when small-bowel evaluation is indicated for obscure gastrointestinal bleeding (strong recommendation, high quality evidence). Computed tomography enterography/enteroclysis may be a complementary examination to capsule endoscopy in selected patients (weak recommendation, low quality evidence).

VCE has been consistently demonstrated to be superior to smallbowel barium radiography in patients with OGIB. In what appears to be the only randomized controlled trial evaluating VCE versus small-bowel radiography in OGIB patients, the diagnostic yield was $30 \%$ with VCE versus $7 \%$ with dedicated small-bowel radiography (difference 23\%; 95\%CI 11\%-36\%) [29]. However, the primary study end point of further bleeding was not statistically different between groups, being 30\% with VCE and $24 \%$ with radiography (difference $6 \%$; $95 \% \mathrm{CI}-9 \%$ to $21 \%$ ). Previously, Triester et al. [14] performed a meta-analysis comparing VCE versus small-bowel barium radiography (small-bowel followthrough [SBFT] or enteroclysis) and reported a diagnostic yield of "clinically significant findings" of $42 \%$ for VCE versus $6 \%$ for small-bowel barium radiography (incremental yield 36\%, 95\%Cl $25 \%-48 \%$; $P<0.001$ ).

VCE is superior to mesenteric angiography/computed tomography (CT)-angiography in determining the cause of bleeding in patients with OGIB. In a randomized controlled trial comparing VCE versus angiography, Leung et al. [30] evaluated the diagnostic yield and long-term outcomes in 60 patients with overt OGIB. 
The diagnostic yield for immediate VCE was significantly higher than for angiography, at $53.3 \%$ versus $20.0 \%$ (difference $33.3 \%$, $95 \%$ CI $8.9 \%-52.8 \%$ ). The cumulative risk of re-bleeding in the angiography and VCE group was $33.3 \%$ and $16.7 \%$, respectively $(P=0.10$, log-rank test). There was no significant difference between the two groups in the long-term outcomes including further transfusion, hospitalization for re-bleeding, and mortality. Furthermore, Saperas et al. [31] reported on a prospective cohort study in which 28 consecutive patients admitted for OGIB underwent both CT-angiography and standard mesenteric angiography, followed by VCE. A source of bleeding was detected by VCE in a greater proportion of patients (diagnostic yield $72 \%, 95 \% \mathrm{CI}$ $50.6-87.9 \%)$, than by CT-angiography (24\%, $95 \%$ Cl $9.4 \%-45.1 \%$; $P=0.005$ vs. VCE), or by angiography ( $56 \%, 95 \%$ CI $34.9 \%-75.6 \%$; $P$ nonsignificant).

The diagnostic yields of VCE and CT-enterography/enteroclysis (CTE) may be dependent upon the underlying causes of OGIB, thus CTE may be a complementary examination to VCE and could be helpful in determining the cause of OGIB in selected patients. In a study by Agrawal et al. [32], 52 patients with OGIB were prospectively enrolled to undergo VCE. CT-enterography was then performed in 25 patients in whom VCE had not identified a definitive source of bleeding. CTE did not identify the source of bleeding in any of the 11 patients with occult bleeding $(0 / 11$, diagnostic yield $0 \%$ ) while the diagnostic yield was $50 \%(7 / 14)$ in patients with obscure overt bleeding $(P<0.01)$, suggesting that when VCE is nondiagnostic, CTE may be useful for detecting a source of gastrointestinal bleeding in patients with overt, but not occult OGIB. The superiority of VCE compared with CTE in OGIB patients was also confirmed also in other studies with diagnostic yields of $57 \%$ and $63 \%$ for VCE and $30 \%$ and $21 \%$ for CTE $[33,34]$. Conversely, Huprich et al. [35], prospectively comparing multiphase CT-enterography and VCE in 58 OGIB patients, reported that the sensitivity of CT-enterography was significantly greater than that of VCE ( $88 \%$ vs $38 \%$, respectively; $P=0.008$ ), largely because $\mathrm{CT}$-enterography found more small-bowel masses ( $100 \%$ vs. $33 \%$, respectively; $P=0.03$ ). A few other small studies (prospective and retrospective case series) have failed to demonstrate any significant difference between VCE and CT-enteroclysis [36-38].

Finally, in a comparative study of 38 OGIB patients, VCE was significantly superior to magnetic resonance enteroclysis for detecting abnormalities [39].

Given the spectrum of findings usually identified in patients with obscure gastrointestinal bleeding, when small-bowel capsule endoscopy is unavailable or contraindicated, ESGE suggests consideration of device-assisted enteroscopy as the first diagnostic test in these patients (weak recommendation, low quality evidence).

ESGE suggests that device-assisted enteroscopy performed with diagnostic intent should be done as soon as possible after the bleeding episode (weak recommendation, low quality evidence).

Studies evaluating the diagnostic accuracy of push-enteroscopy and device-assisted enteroscopy in patients with OGIB (occult and overt) are scarce. One trial used a combined criterion standard (including results from other procedures and/or outcomes during follow-up) to calculate the sensitivity, specificity, PPV, and NPV of DBE in the diagnosis of small-intestinal lesions in OGIB patients, and found values of $92.7 \%, 96.4 \%, 98.1 \%$, and
$87.1 \%$, respectively [40]; these figures are similar to those already known for VCE [10]. As with VCE, the outcome that is most frequently reported is diagnostic yield. In patients with OGIB (including both occult and overt) the diagnostic yield of push-enteroscopy is approximately $25 \%-35 \%$ [ $41-43$ ] and that of double-balloon enteroscopy is 55\% [12], being generally higher in those with overt bleeding. As far as device-assisted enteroscopy is concerned, although the majority of published studies were performed with double-balloon enteroscopy and significant differences among device-assisted enteroscopy devices have been reported (i.e. depth of small-bowel intubation, rate of complete enteroscopy), clinical outcomes, namely diagnostic yield, seem to be consistently similar across studies, regardless of the device used [44-48].

When push-enteroscopy and device-assisted enteroscopy are prospectively compared, the overall diagnostic yield is significantly higher for device-assisted enteroscopy [49]. On the other hand, when lesions located in the proximal small bowel are considered, the diagnostic yield appears to be comparable between the two techniques [50-52]. However, sedation, examination time and X-ray exposure are lower with push-enteroscopy. Therefore, push-enteroscopy could represent a reliable diagnostic tool when a lesion is known to be located in the proximal small bowel.

When CT-enterography/enteroclysis (CTE) is compared with DBE in OGIB patients, the diagnostic yield of DBE is significantly higher [53-55]. The diagnostic yield of CT-enterography increases significantly when a small-bowel tumor is suspected [35]; in this subset of patients CTE should precede device-assisted enteroscopy.

The available studies evaluating the performance of CT-angiography in patients with OGIB, including both occult and overt bleeding, showed diagnostic performances inferior to device-assisted enteroscopy [31]. However, when patients with overt OGIB were selected, both techniques yielded similar results $[56,57]$. Adequately powered studies, with head-to-head comparison of device-assisted enteroscopy versus CT-angiography in patients with occult and overt OGIB, are lacking, as are studies comparing magnetic resonance enterography/enteroclysis and deviceassisted enteroscopy.

The optimal timing of device-assisted enteroscopy has not yet been clearly determined; however, proximity to the bleeding episode seems to confer higher diagnostic yields. For patients with overt OGIB the diagnostic yield of device-assisted enteroscopy significantly increases if the procedure is performed early (within 1 month) after clinical presentation [58].

ESGE suggests that emergency small-bowel capsule endoscopy should be considered in patients with ongoing overt obscure gastrointestinal bleeding (weak recommendation, moderate quality evidence).

In such patients, ESGE suggests that device-assisted enteroscopy should also be considered as a possible first-line test, given that it allows diagnosis and treatment in the same procedure (weak recommendation, low quality evidence).

The prospect of utilizing VCE for severe ongoing overt OGIB is appealing because of the relative safety, ease, and feasibility of the procedure in this setting. In addition, it has already been established, that early performance of VCE confers a superior diagnostic yield that translates to better patient management and out- 
comes $[10,17,18,22,26,59]$. Specifically with regard to urgent VCE, only two retrospective studies $[60,61]$ and one randomized controlled trial [30], involving fewer than 100 patients overall, have been reported so far. Based on limited data, emergency VCE, performed within 24-72 h from admission, during severe ongoing overt OGIB, appears to be an effective modality, with a diagnostic yield up to $70 \%$ and a significant impact on patient management.

Data are limited on the role of emergency device-assisted enteroscopy for the diagnosis and treatment of severe overt OGIB. In a small study of 10 patients with ongoing overt OGIB, emergency DBE was performed within 24 hours of clinical presentation and showed a diagnostic and therapeutic yield of $90 \%$ [56]. In a separate retrospective report of 120 patients with overt OGIB, urgent DBE was defined when the examination was done within $72 \mathrm{~h}$ after the last visible gastrointestinal bleeding; in this study the diagnostic yield in urgent DBE $(70 \%, 52 / 74)$ was significantly higher than that in non-urgent DBE $(30 \%, 14 / 46 ; P<0.05)$ [62].

Notably, data from a small retrospective study showed that a combined approach, with emergency DBE guided in real time by VCE, is feasible in selected patients with acute overt OGIB [63]. Thus, in patients with ongoing overt OGIB, device-assisted enteroscopy should also be considered as first-line endoscopy, given the ability for diagnosis and treatment in the same procedure, and especially in centres where this modality is readily available and there is expertise in therapeutic enteroscopy. The optimal strategy for the evaluation of these patients remains undefined however, and this should be clarified with prospective studies.

ESGE does not recommend the routine performance of second-look endoscopy prior to small-bowel capsule endoscopy; however whether to perform second-look endoscopy before capsule endoscopy in patients with obscure gastrointestinal bleeding or iron-deficiency anaemia should be decided on a case-by-case basis (strong recommendation, low quality evidence).

Although several studies have reported a significant lesion detection rate for VCE in the stomach/duodenum or colon in OGIB patients, the limited available data suggest a low yield in these patients from systematic repeat oesophagogastroduodenoscopy (OGD) and/or ileocolonoscopy (i.e., second-look endoscopy) prior to VCE. Selby et al. reported on 92 patients with OGIB and showed that, at VCE, lesions were found as often in patients who had received only one preceding endoscopic evaluation as in those who had multiple endoscopic procedures [64]. Subsequently Gilbert et al., from this same author group, performed repeat endoscopies (OGD plus ileocolonoscopy) prior to VCE in 50 patients referred for the investigation of OGIB [65]. A probable cause of bleeding was found on repeat EGD in only 2/50 (4\%) and repeat colonoscopy revealed no additional sources of bleeding. The authors concluded that the yield of repeat OGD and colonoscopy immediately prior to VCE is low when these procedures have previously been nondiagnostic. They also concluded that this approach was not cost-effective. Similarly, Vlachogiannakos et al. [66] in a retrospective analysis of 317 patients who underwent VCE for OGIB (after previous negative OGD and colonoscopy) reported that in $3.5 \%$ of cases, the source of bleeding was found in the stomach or the caecum. Routine repetition of conventional endoscopy before VCE was not a cost-effective approach.
To date, there are no time- or referral-based criteria for selecting patients in whom it may be worthwhile to perform second-look endoscopy before VCE. At the present time, the decision to perform second-look endoscopy before VCE in patients with OGIB or iron-deficiency anaemia (see below) should be taken only on a case-by-case basis.

ESGE recommends conservative management in those patients with obscure gastrointestinal bleeding (OGIB) and a negative small-bowel video capsule endoscopy (VCE) who do not have ongoing bleeding shown by overt bleeding or continued need for blood transfusions, since their prognosis is excellent and the risk of re-bleeding is low. ESGE recommends further investigation using repeat VCE, device-assisted enteroscopy, or computed tomography-enterography/enteroclysis for patients with OGIB and a negative VCE who have ongoing bleeding shown by overt bleeding or continued need for blood transfusions (strong recommendation, moderate quality evidence).

Up to one third of patients undergoing VCE for OGIB will have a negative VCE. Several studies have shown that in most patients with normal findings at VCE, re-bleeding rates and the need for transfusions are low. A total of 49 patients who underwent VCE for OGIB were followed up for a mean of 19 months; the overall long-term re-bleeding rate was $32.7 \%$. The cumulative re-bleeding rate was significantly lower in patients with negative VCE (5.6\%) than in patients with positive VCE (48.4\%) [67]. In another study [68], 42 patients with OGIB were followed up for a mean of 17 months after VCE. The overall re-bleeding rate was $28 \%$, and there was a statistically significant difference in re-bleeding rates between patients with positive findings (re-bleeding in $42 \%$ ) and those with negative findings (re-bleeding in $11 \%$ ); both in this last study and in another more recent report [69], anticoagulant use was associated with an increased risk of re-bleeding.

Although other studies on this topic have come to different conclusions [70] several reviews and consensus recommendations $[71,72]$ have concluded that patients with OGIB and normal findings at VCE should be managed conservatively without further investigation. Such conservative management may include a "wait and see" policy or iron supplementation or blood transfusions to restore haemoglobin levels.

Nevertheless, in cases of ongoing overt bleeding or continuing need for blood transfusions an alternative approach is warranted. In such patients, repeat VCE can yield a positive finding, and especially in patients with a drop in haemoglobin of at least $4 \mathrm{~g} / \mathrm{dL}$ or in those with a change in clinical presentation from occult to overt bleeding [73]. Alternatively, device-assisted enteroscopy [74,75] or CT-enterography/enteroclysis [32] can be performed after an initial negative VCE, and can yield a positive finding. At present there are no available data about the performance of CTangiography in this setting. Similarly, there are no data about repeating upper and lower gastrointestinal endoscopy specifically in these patients although there is indirect evidence $[65,66]$ suggesting that these investigations can identify lesions previously overlooked. Randomized controlled trials comparing these modalities in the subgroup of patients with a nondiagnostic initial capsule study are still needed to clarify the most appropriate management. 
In patients with positive findings at small-bowel capsule endoscopy, ESGE recommends device-assisted enteroscopy to confirm and possibly treat lesions identified by capsule endoscopy (strong recommendation, high quality evidence).

Teshima et al. [12] found that the pooled diagnostic yield of DBE performed after a previously positive VCE was 75.0\% (95\%CI $60.1 \%$-90\%); the odds ratio for the yield of DBE performed after a previously positive VCE, compared with that of DBE performed in all patients, was $1.79(95 \% \mathrm{CI} 1.09-2.96 ; P=0.02)$. In that same study, a subgroup analysis revealed that the pooled diagnostic yield of DBE performed after a previously negative VCE was $27.5 \%$ (95\%CI $16.7 \%-37.8 \%$ ). In addition to its therapeutic possibilities, DBE has been reported to be helpful in clarifying the origin of bleeding when VCE shows only blood in the lumen or doubtful findings [76].

Although studies have assessed the diagnostic yield of VCE, pushenteroscopy, and device-assisted enteroscopy in OGIB, the precise significance of lesions identified and the impact on clinical outcome has not been consistently evaluated for those modalities. When we consider outcome in clinical practice, the emphasis should be on meaningful results. In the case of OGIB, a positive patient outcome should be either cessation of bleeding or resolution of anaemia. In addition, other important clinical outcomes for evaluation may include mortality and hemoglobin levels as well as the reduction in numbers of endoscopic procedures, hospitalizations, and blood transfusions. Several studies have demonstrated change in patient management and improved outcomes following VCE $[10,18,19]$ and device-assisted enteroscopy [58,77-81]. However, prospective comparative trials have not consistently confirmed these results $[25,29,30]$.

\section{Iron-deficiency anaemia}

In patients with iron-deficiency anaemia, ESGE recommends that prior to small-bowel capsule endoscopy, all the following are undertaken: acquisition of a complete medical history (including medication use, co-morbidities, and gynaecological history in premenopausal females), oesophagogastroduodenoscopy with duodenal and gastric biopsies, and ileocolonoscopy (strong recommendation, low quality evidence).

Iron-deficiency anaemia (IDA) occurs in $2 \%-5 \%$ of adult men and postmenopausal women in developed countries and is a common reason for referral to gastroenterologists [82]. According to the most recently published practice guidelines, upper and lower gastrointestinal endoscopy are the cornerstone of the investigation of IDA (particularly in postmenopausal women and all male patients). Bi-directional endoscopy identifies the cause of IDA in $70 \%-80 \%$ of patients. When findings are negative, the small bowel is often targeted for further investigation [82].

Although there are no data comparing the effect of different selection criteria on the diagnostic performance of small-bowel video capsule endoscopy (VCE), the studies applying strict criteria tend to have a higher diagnostic yield [83-85]. Therefore, it is advisable that in patients with IDA referred for small-bowel evaluation, a complete work-up should be performed including: bidirectional endoscopy (with ileoscopy whenever possible); exclusion of coeliac disease (through serological and/or histopatho- logical investigation); the taking of a complete past medical history (paying particular attention to medications and co-morbidities); gynaecological evaluation (for premenopausal women), and haematological evaluation.

In IDA patients, some authors have reported an increased incidence, higher than that reported in OGIB studies, of lesions detected by VCE that were within the reach of conventional endoscopy [86-89]; they also reported that after positive VCE, up to $30 \%$ of patients with lesions identified by VCE have been managed by repeating oesophagogastroduodenoscopy or colonoscopy. Unfortunately, there is a lack of studies evaluating the cost-effectiveness of a systematic second-look endoscopy before smallbowel exploration in IDA patients. Therefore, at the present time, the decision to perform a second-look endoscopy before small-bowel exploration should be taken on a case-by-case basis. Recently published guidelines recommend an empirical trial of iron supplementation before referring patients for small-bowel evaluation [82]. Some initial data seem to support this policy, showing an increased diagnostic yield from VCE in patients in whom IDA persists or recurs after an empirical iron trial [90]. Nevertheless such a trial would lead to a diagnostic delay that might not be appropriate in some subgroups of patients (i.e. young patients or those with other associated gastrointestinal symptoms). Further large studies are needed to better clarify the diagnostic work-up to be performed before VCE in IDA patients. In patients with OGIB the role of the faecal occult blood test (FOBT) as a possible selection test has also been investigated. Unfortunately, studies are scarce and have yielded conflicting results [91,92]. Further studies are needed and, at present, FOBT cannot be recommended as a screening tool to select patients for VCE.

In patients with iron-deficiency anaemia, ESGE recommends performance of small-bowel capsule endoscopy as a first-line examination, before consideration of other diagnostic modalities, when upper and lower gastrointestinal endoscopies are inconclusive and small-bowel evaluation is indicated (strong recommendation, moderate quality evidence).

In a systematic review, Koulaouzidis et al. [93] reported that pooling data from four studies focused on IDA [83-85,94] gave a diagnostic yield for VCE of $66 \%$ (95\%CI $61.0 \%-72.3 \%)$, which is comparable to that reported in other studies on the same topic $[11,86,89]$. Nevertheless, other recent studies [19, 88,95-97] have reported a lower diagnostic yield, ranging between $25 \%$ and $48 \%$. Pooling together all studies focused on IDA [83-86,88, $89,94-96$ ] the overall diagnostic yield of VCE in IDA patients is $53 \%$ (95\%CI $41 \%-65 \%)$.

While there are no studies specifically designed to evaluate the diagnostic yield of push-enteroscopy and device-assisted enteroscopy in IDA patients, nevertheless, several studies focused on OGIB patients had IDA as part of their inclusion criteria. Thus the diagnostic yield of push-enteroscopy/device-assisted enteroscopy in IDA patients should be similar to that reported in occult OGIB patients. In those studies, the diagnostic yield of push-enteroscopy varies widely (range $30 \%-70 \%$, mean approximately $40 \%$ ) [41,98-102] whereas the diagnostic yield of device-assisted enteroscopy appears comparable to that of VCE. In a prospective randomized trial, comparing VCE with push-enteroscopy, De Leusse et al. [25] found that VCE has a higher diagnostic yield ( $50 \%$ vs. $24 \%, P<0.05)$. Although this study evaluated OGIB pa- 
tients (half of the referrals for small-bowel exploration were for IDA), they reported that the yield of the diagnostic procedures was not significantly influenced by the nature of the OGIB: therefore we can assume that VCE is superior to push-enteroscopy even when only IDA patients are concerned. Retrospective observational studies $[97,99,103,104]$ reporting the diagnostic yield of push-enteroscopy in IDA, which is about $25 \%-35 \%$, appear to support this hypothesis.

There are no head-to-head studies comparing device-assisted enteroscopy and VCE in IDA patients. Studies reporting the diagnostic yield of device-assisted enteroscopy, when used as a primary diagnostic tool in IDA, are scarce and include only a small number of patients [105]. Once again, looking at the diagnostic yield of device-assisted enteroscopy in OGIB patients only (particularly those with obscure-occult bleeding), it appears to be comparable to that of VCE $[12,15]$, especially when a complete enteroscopy is achieved [11]. Similar diagnostic yields might be reasonably expected in IDA patients, also.

In the setting of IDA there are two prospective studies comparing VCE and radiological examination head-to-head. Once again, this comparison is based on diagnostic yield rather than accuracy. VCE has been found to be significantly superior to small-bowel enteroclysis (diagnostic yield $56.9 \%$ vs. $11.8 \%, P<0.001$ ) [94] and to CT-enteroclysis (diagnostic yield: $77.8 \%$ vs. $22.2 \%, P<0.01$ ) [84]. The success of VCE over radiological techniques in IDA patients is mostly related to the nature of findings that, in $50 \%-$ $60 \%$ of cases, are small flat vascular lesions [106]. There are no studies comparing magnetic resonance enterography/enteroclysis and VCE in IDA patients.

With regard to factors potentially associated with a positive diagnosis in IDA patients, a favourable association between increased VCE diagnostic yield and greater age and severity of anaemia has been found $[83,95,96]$; nevertheless, because of the incidence of important findings in young patients, age alone cannot be recommended as a reliable criterion for patient selection [96,107]. Potential positive associations between diagnostic yield of VCE and concomitant anticoagulation therapy, as well as the presence of co-morbidities, have been suggested and need to be verified by further studies $[83,95,96,108]$. There are no data about factors affecting the diagnostic yield of device-assisted enteroscopy as the primary diagnostic tool in IDA patients.

At present, there are few studies evaluating the long-term outcome of IDA patients who undergo small-bowel evaluation. Furthermore, the existing studies are retrospective and heterogeneous in terms of patient characteristics, length of follow-up, modalities, and work-up done after the small-bowel examinations. Two studies evaluating the impact of VCE in IDA patients $[86,95]$, reported that overall VCE results led to changes in management, regardless of the result of VCE, in $44 \%$ and $60 \%$ of patients. This is more evident when the analysis is restricted to patients with positive VCE findings. Taking into account both specific therapeutic interventions and iron supplementation, change in management occurs in the large majority (up to 100\%); however when specific interventions only are included (i.e., specific medical therapy, such as steroids, lanreotide, thalidomide, or gluten-free diet, or surgical/endoscopic therapy), changes in management are observed in $30 \%-50 \%$ of patients with positive VCE findings. Some studies $[86,89,94]$ reported that the rate of resolution of anaemia at the end of follow-up is high (range 57\%-86\%), but yielded conflicting results when comparing patients with positive and negative VCE findings. While Apostolopoulos et al. [94] reported a significant difference in the rate of anaemia resolution between patients with positive and negative VCE findings ( $100 \%$ vs. $68 \%, P<0,05$ ), both Sheibani et al. [89] and Holleran et al. [86] did not find any difference between these two groups. There are no studies evaluating the clinical outcome of other diagnostic tools for small-bowel evaluation when used as the primary diagnostic method in IDA patients.

Regarding safety in IDA patients, VCE has shown an excellent safety profile (similar to that observed in OGIB; capsule retention range $0 \%-4 \%[84]$ ), whereas there are no specific data about the safety of device-assisted enteroscopy in IDA patients. Nevertheless, a complication rate comparable to that observed in OGIB patients can be expected for device-assisted enteroscopy.

Regarding costs, there are no data on the cost-effectiveness of different diagnostic approaches for the evaluation of the small bowel in IDA patients. This is the main target for further studies, namely to take into account not only efficacy but also local costs and reimbursement policies, which differ widely among countries and health care systems.

\section{Crohn's disease \\ $\nabla$}

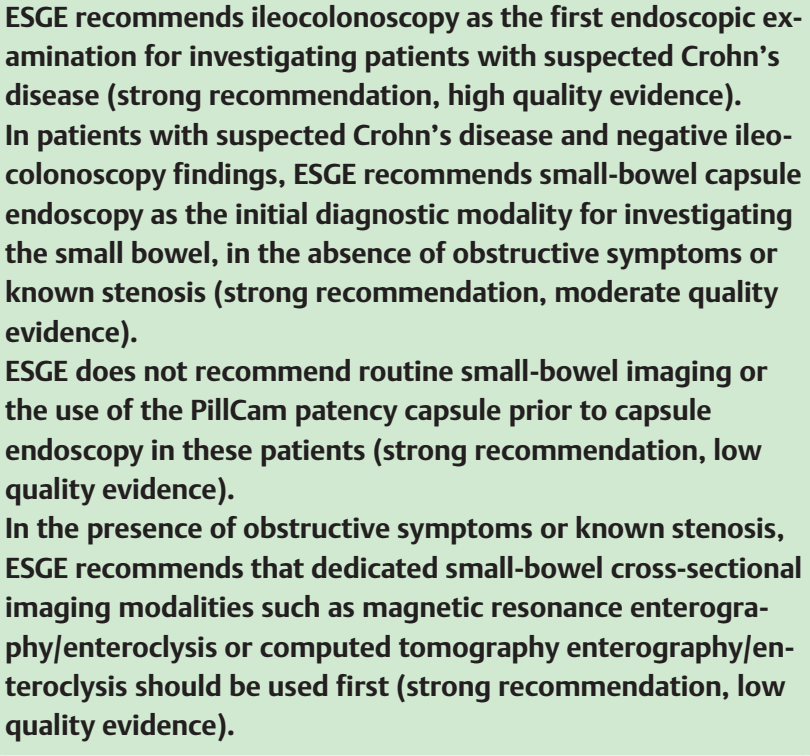

Up to $66 \%$ of patients with Crohn's disease have small-bowel involvement at diagnosis [109] and in approximately $90 \%$ of patients with small-bowel Crohn's disease, the disease involves the terminal ileum [110]. Thus, ileocolonoscopy is considered to be the first-line investigation for Crohn's disease and is sufficient to establish the diagnosis in the vast majority of patients [109].

However, skip lesions of the terminal ileum may result in falsenegative results at ileocolonoscopy [111] and small-bowel video capsule endoscopy (VCE) should therefore be considered when retrograde ileoscopy is not achieved or when lesions in the proximal small bowel must be excluded. VCE has been shown to have consistently high sensitivity and a high negative predictive value that ranges from $96 \%$ to $100 \%$ [112-116]. However, the lack of a gold standard for the diagnosis of Crohn's disease hinders precise determination of VCE accuracy for this condition and "diagnostic yield" for findings consistent with Crohn's disease has often been adopted as a surrogate in the appropriate clinical context. Furthermore, the mucosal inflammatory changes which are found in active small-bowel Crohn's disease, are not specific to this dis- 
ease and this has fuelled debate about where VCE should fit within the diagnostic algorithm for Crohn's disease [117,118]. The high diagnostic yield of VCE compared with other imaging modalities might therefore not translate directly into a higher diagnostic accuracy since lesions detected by VCE might also be induced by other causes [119] such as nonsteroidal anti-inflammatory drugs (NSAIDs) in particular [120-124]. Moreover, VCE may detect minor mucosal breaks and erosions in up to one fifth of healthy individuals $[113,125]$. Nonetheless, VCE has been shown to compare favourably with small-bowel cross-sectional imaging for the detection of mucosal lesions consistent with Crohn's disease $[119,126]$.

In a meta-analysis conducted by Dionisio et al. [126] VCE was found to be superior to small-bowel follow-through (SBFT)/ small-bowel enteroclysis and computed tomography enterography/enteroclysis (CTE), with significant weighted incremental yields in patients with suspected Crohn's disease (VCE 52\% vs. SBFT/small-bowel enteroclysis 16\%, incremental yield $32 \%, P<$ $0.0001,95 \%$ CI $16 \%$ - 48\%; VCE $68 \%$ vs. CT-enterography $21 \%$, incremental yield $47 \%, P<0.00001,95 \% \mathrm{CI} 31 \%-63 \%$ ). A recent prospective study confirmed that VCE was better than SBFT and equivalent to ileocolonoscopy in detecting small-bowel inflammation in patients with suspected Crohn's disease; this study also suggested that VCE can establish the diagnosis of Crohn's disease in patients with proximal small-bowel inflammation, when ileocolonoscopy is negative [127]. Some recent studies have shown that VCE may be superior to magnetic resonance enterography/enteroclyis (MRE), particularly for the detection of early disease and proximal small-bowel lesions [128-130]. Although MRE and CTE have been shown to have a similar accuracy for the detection of inflammation in Crohn's disease [131-135], MRE has the advantage of being free from ionizing radiation, a factor of increasing concern in the medical community [136] and increasing awareness amongst patients [137], but is limited by higher cost, longer examination time, and slightly inferior spatial resolution [131]. In a previous prospective, blinded randomized controlled trial by Solem et al. [138], which compared VCE, CTE, SBFT, and ileocolonoscopy in patients with known or suspected Crohn's disease (using a consensus clinical diagnosis as the reference "gold standard"), the sensitivity of VCE and CTE was similar (83\% for VCE, 67\% for CTE and ileocolonoscopy, and $50 \%$ for SBFT) but the specificity of VCE was lower (53\%) than that of all other tests $(100 \%, P<0.05)$. The results of this key study highlight the importance of interpreting VCE findings within an appropriate and well-defined clinical context.

The risk of capsule retention in patients with suspected Crohn's disease but without obstructive symptoms or known stenosis and no history of small-bowel resection is low ( 1.6\%) and similar to that of patients who are being investigated for OGIB [13, 139-142]. In patients with suspected Crohn's disease and a negative ileocolonoscopy, small-bowel stricturing disease is infrequent and in the absence of suspicious clinical symptoms, routine small-bowel imaging or use of the PillCam patency capsule prior to VCE is not essential. A careful clinical history may be the most useful way to determine the risk of capsule retention in this setting $[140,143]$. If patients with suspected Crohn's disease present with obstructive symptoms or suspected/known stenosis, dedicated small-bowel cross-sectional imaging in the form of CTE or MRE (which may also provide additional evaluation of mural and extramural disease) should be the method of choice. VCE may still be used in this setting if functional patency of the small-bow- el is confimed with the use of the PillCam patency capsule [144146].

In the setting of suspected Crohn's disease, ESGE recommends careful patient selection (using the clinical history and serological/ faecal inflammatory markers) prior to small-bowel capsule endoscopy, in order to improve the diagnostic accuracy of capsule endoscopy for lesions consistent with active small-bowel Crohn's disease (strong recommendation, low quality evidence).

ESGE recommends discontinuation of nonsteroidal anti-inflammatory drugs (NSAIDs) for at least 1 month before capsule endoscopy since these drugs may induce small-bowel mucosal lesions indistinguishable from those caused by Crohn's disease (strong recommendation, low quality evidence).

Careful patient selection remains crucial to increasing the specificity and positive predictive value (PPV) of VCE findings. At present, no specific index for the diagnosis of Crohn's disease exists and although the presence of clinical symptoms remains an important trigger of the diagnostic process, abdominal pain or chronic diarrhoea alone rarely result in the detection of clinically significant small-bowel lesions at VCE $[147,148]$. Some more objective predictive clinical markers of small-bowel Crohn's disease include the presence of weight loss [149], perianal disease [150], raised inflammatory markers [151-154], and faecal calprotectin levels [155-157]. The International Conference on Capsule Endoscopy (ICCE) [71] recommended that patients with suspected Crohn's disease may be appropriate candidates for VCE only if they present with typical symptoms in addition to either extraintestinal manifestations of Crohn's disease, raised serological/haematological inflammatory markers and/or iron deficiency, and/or abnormal small-bowel imaging findings (e.g. from SBFT and/or CTE/MRE).

Faecal calprotectin has recently been shown to be a sensitive marker of intestinal inflammation [158] and has potential as a cost-effective measure for selection of patients with suspected or known Crohn's disease who are under consideration for VCE $[155-157,159,160]$.

Use of nonsteroidal anti-inflammatory drugs (NSAIDs) may be complicated by a drug-induced enteropathy with small-bowel mucosal erosion and ulceration which may lead to the formation of short, diaphragm-like strictures $[161,162]$. Several VCE studies have shown that use of NSAIDs (both nonselective and selective Cox-2 inhibitors) may be associated with a high incidence of small-bowel erosion and ulceration (of the order of $55 \%$ to $75 \%$ ) [121-124,163-165]; chronic use of low dose aspirin has also been shown to be associated with the presence of similar smallbowel lesions $[166,167]$. Since the endoscopic appearances of small-bowel lesions induced by NSAIDs are endoscopically indistinguishable from lesions with other aetiologies such as Crohn's disease, their presence may be confounding and potentially lead to misdiagnosis. In view of this, NSAIDs should be stopped before VCE, particularly if the patient is being investigated for the presence of active small-bowel Crohn's disease. Although recommendations in the current literature are heterogeneous, arbitrarily stopping these agents for at least 1 month before VCE appears to be an acceptable prudent strategy [123]. 
In patients with established Crohn's disease, based on ileocolonoscopy findings, ESGE recommends dedicated crosssectional imaging for small-bowel evaluation since this has the potential to assess extent and location of any Crohn's disease lesions, to identify strictures, and to assess for extraluminal disease (strong recommendation, low quality evidence). In patients with unremarkable or nondiagnostic findings from such cross-sectional imaging of the small bowel, ESGE recommends small-bowel capsule endoscopy as a subsequent investigation, if deemed to influence patient management (strong recommendation, low quality evidence).

When capsule endoscopy is indicated, ESGE recommends use of the PillCam patency capsule to confirm functional patency of the small bowel (strong recommendation, low quality evidence).

In patients with known Crohn's disease, irrespective of the findings at ileocolonoscopy, further investigation is recommended to assess the extent and location of any Crohn's disease lesions in the more proximal small bowel, since any positive findings may have prognostic and therapeutic implications [109]. Dedicated small-bowel cross-sectional imaging with CTE or MRE generally takes precedence over VCE for the evaluation of the small bowel in patients with established Crohn's disease, since these modalities may also identify strictures and have the ability to assess the transmural and extraluminal nature of the disease and its anatomical distribution [117].

Dionisio et al. [126] showed in a meta-analysis that VCE was superior to SBFT/small-bowel enteroclysis and CTE in the evaluation of patients with known Crohn's disease, with a significantly higher diagnostic yield (VCE 71\% vs. SBFT/small-bowel enteroclysis $36 \%$, incremental yield $38 \%, P<0.00001,95 \%$ CI $22 \%-54 \%$; VCE $71 \%$ vs. CTE $39 \%$, incremental yield $32 \%, P \leq 0.0001,95 \% \mathrm{CI}$ $16 \%-47 \%$ ). On the other hand, the diagnostic yield of VCE was found to be inferior to that of MRE, at 70\% versus 79\% (incremental yield $-6 \%, P=0.65,95 \% \mathrm{CI}-30 \%$ to $19 \%$ ). Nonetheless, VCE has been shown to improve the detection of lesions in the proximal small bowel when compared with both CTE and MRE $[128,168]$ and may detect proximal small-bowel lesions in up to $50 \%$ of patients with previously diagnosed ileal Crohn's disease [169]. Despite the suggestion from a recent study that CTE or MRE may be sufficient for the investigation of most patients with known small-bowel Crohn's disease [170], VCE may still be of value if a Crohn's disease flare-up is still suspected despite negative results from small-bowel cross-sectional imaging. In this context, VCE may be used as a further investigation if the presence of smallbowel mucosal lesions may influence patient management. Although prospective controlled trial data are lacking, a few retrospective studies have highlighted the potential impact of VCE on the management of patients with established Crohn's disease [171-178].

The risk of capsule retention is increased and can be of the order of $13 \%$ in patients with known Crohn's disease [13,140-142, $179,180]$. Although findings of small-bowel stenosis at CTE or MRE may preclude subsequent VCE in $27 \%$ to $40 \%$ of patients with known Crohn's disease [131], not all strictures actually result in significant mechanical obstruction and the use of the PillCam patency capsule may help to identify patients who are at increased risk of capsule retention [144]. One retrospective study compared the performance of the patency capsule and radiological examinations in the detection of clinically significant small- bowel strictures [145]. In this study, the two methods were equivalent, suggesting that if cross-sectional imaging shows no stricture or the patency capsule is excreted intact, the patient will most probably pass the video capsule safely.

ESGE recommends initial conservative treatment in the case of capsule retention. ESGE recommends device-assisted enteroscopy if medical therapy has not led to promote spontaneous passage (strong recommendation, low quality evidence).

Cases of capsule retention can often be managed conservatively with anti-inflammatory agents and/or immunomodulators [181], resulting in spontaneous passage of the capsule [182]. If the capsule does not pass spontaneously after a trial of medical therapy, it may be retrieved by device-assisted enteroscopy $[183,184]$. If attempts at endoscopic capsule retrieval are unsuccessful and the patient is clinically well and without obstructive symptoms, an observant, conservative approach may be appropriate in this setting and only a minority of patients will need to undergo surgery to retrieve a retained capsule. In a large retrospective study of 2300 patients [185], including 301 with known Crohn's disease of whom 196 (65.1\%) had definite small-bowel involvement, capsule retention occurred in only 5 patients (1.66\%). In 3 of these patients, the capsule passed spontaneously after a course of glucocorticoid therapy, while the other 2 patients required surgery for capsule retrieval.

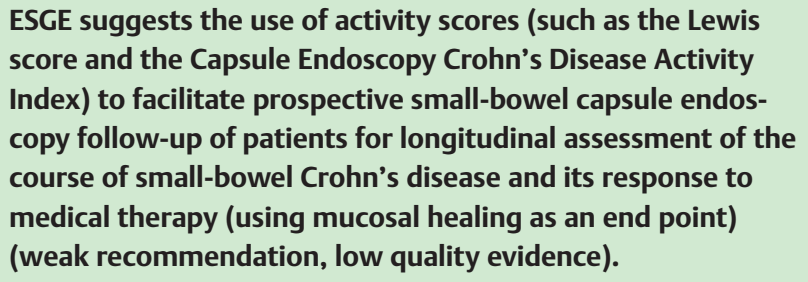

The introduction of standardized quantitative scoring systems to describe the type, location, and severity of small-bowel lesions is being attempted [186]. The original threshold of $\geq 3$ ulcers proposed by Mow et al. [114], although widely used, does not reflect the distribution or the severity of inflammatory activity, does not consider other inflammatory features such as oedema or stenosis, and has a modest positive predictive value of $50 \%-69 \%$ for the diagnosis of Crohn's disease $[113,171,187]$. The Capsule Endoscopy Crohn's Disease Activity Index (CECDAI) score evaluates three parameters of small-bowel pathology in Crohn's disease: inflammation, extent of disease, and presence of strictures, both for the proximal and distal segments of the small bowel, based on small-bowel transit time of the capsule. This score has been recently validated in a multicentre prospective study [188, 189]. The Lewis score [190], which has also recently been validated [191], is a cumulative scoring system that is based on the presence and distribution of villous oedema, ulceration, and stenosis. It should be borne in mind that although these scoring systems can quantitatively describe the type, distribution, and severity of mucosal lesions, they cannot be used as a diagnostic tool per se [192]. In view of the nonspecific nature of small-bowel inflammatory lesions, the results of these scoring systems must be interpreted in the appropriate clinical context, in conjunction with other findings; it must be emphasised that a diagnosis of ac- 
tive small-bowel Crohn's disease cannot be based upon the appearances seen only at VCE.

Mucosal healing is increasingly recognised as an important end point for assessment of therapeutic efficacy in patients with inflammatory bowel disease (IBD). Recent clinical trials have begun to evaluate the potential role of VCE for assessment of mucosal healing in the small bowel [193 - 195], using quantitative scores such as the Lewis score [190] or CECDAI [189] for this purpose in research trials and clinical practice, analogously to the application to ileocolonoscopy of the Crohn's Disease Endoscopic Index of Severity (CDEIS) or the Simple Endoscopic Score (SES) for Crohn's disease [196].

The potential role of VCE in the assessment of patients with IBD unclassified (IBDU) has also been investigated. Although current data are scant, there is a suggestion that the findings at VCE may help to establish a definite diagnosis and small-bowel lesions compatible with Crohn's disease may be seen in up to $17 \%-70 \%$ of patients with this condition [171,197-199]. However, it must be borne in mind that a negative VCE rules out only current disease activity and cannot definitely exclude a future diagnosis of Crohn's disease in these patients $[200,201]$.

In the natural course of Crohn's disease, intestinal resection is unavoidable in a significant proportion of patients. A majority of patients develop disease recurrence at or above the anastomosis and endoscopically detectable recurrence precedes the development of clinical symptoms. Although VCE has been shown to detect superficial proximal small-bowel lesions, undiagnosed by other modalities, in patients with Crohn's disease early after surgery, the clinical significance of these findings and how they may impact on patient management remains a matter of debate [202]. Therefore VCE should not at present replace ileocolonoscopy in the routine management of patients after surgery; it should be considered in the assessment of postoperative recurrence when ileocolonoscopy is unsuccessful or contraindicated [203-206].

ESGE recommends device-assisted enteroscopy with small-bowel biopsy in patients with noncontributory ileocolonoscopy and with suspicion of Crohn's disease on small-bowel cross-sectional imaging modalities or small-bowel capsule endoscopy. Device-assisted enteroscopy with small-bowel biopsy is more likely to provide definitive evidence of Crohn's disease than cross-sectional imaging, although the latter offers a useful less invasive alternative that better defines transmural complication (strong recommendation, high quality evidence).

Although there is no gold standard for the diagnosis of Crohn's disease and corroboration of clinical and investigative findings is required [109], the likelihood of its presence can be supported by the findings at ileocolonoscopy in the majority of patients with suspected Crohn's disease [119]. Dedicated small-bowel crosssectional imaging (CTE or MRE) should be considered if symptoms raise suspicion for the presence of stricturing or perforating disease. These modalities are complementary to VCE which in turn is more sensitive in detecting mucosal inflammation [116, $126,207]$. Push-enteroscopy may provide direct endoscopic assessment and biopsies for histopathology especially in patients whose prior radiological or VCE findings suggest a lesion within the proximal small bowel $[99,208,209]$. Lesions that lie deeper in the small bowel, beyond the reach of ileocolonoscopy and pushenteroscopy, may be accessed by device-assisted enteroscopy which should be considered if histological assessment is needed to confirm a diagnosis of Crohn's disease or to exclude other conditions which mimic the appearance of Crohn's disease, such as infections or malignancy [210-215].

In the setting of suspected small-bowel Crohn's disease, the diagnostic yield of device-assisted enteroscopy ranges between $22 \%$ and $70 \%[210,211,216]$, being higher if the indication for device-assisted enteroscopy is based on previous small-bowel investigations (which may identify suspected lesions and guide the choice of insertion route) [211]. Two meta-analyses [15,16] showed that VCE and double-balloon enteroscopy (DBE) have similar diagnostic yields. The authors concluded that in view of its noninvasive nature, VCE should be considered first.

In the setting of patients with established Crohn's disease, the presence of small-bowel strictures may limit the safe use of VCE and as a result, device-assisted enteroscopy may be considered earlier in the evaluation of such patients [217]. Device-assisted enteroscopy may allow complete small-bowel examination and has a higher yield in patients where a high clinical index of suspicion for active Crohn's disease persists. In such a setting, compared with radiological modalities, device-assisted enteroscopy seems to be more accurate than small-bowel barium contrast studies [218] and MRE $[219,220]$. As for other settings, positive findings at device-assisted enteroscopy were more likely if these investigations were guided by the findings of prior diagnostic imaging; this might also identify the optimal insertion route $[28,211,221]$.

Device-assisted enteroscopy, however, is technically challenging, may require a bi-directional approach, deep sedation, or general anaesthesia and has a major complication rate of around $0.72 \%$ (which may be higher in patients with Crohn's disease) [222]. Therefore it should only be done if it might alter therapeutic strategy. In a small prospective trial, positive findings at deviceassisted enteroscopy led to a step-up of medical therapy in 26 of 35 patients (74\%), leading to clinical remission in 23 (88\%) [217].

ESGE recommends device-assisted enteroscopy if small-bowel endotherapy is indicated (including dilation of Crohn's disease small-bowel strictures, retrieval of foreign bodies, and treatment of small-bowel bleeding) (strong recommendation, low quality evidence).

Reported indications for device-assisted enteroscopy in the setting of known or suspected Crohn's disease include diagnosis and therapeutic endoscopy in patients with bleeding [211,218], balloon dilation of strictures in symptomatic patients, and retrieval of retained capsules $[211,223]$. Technical success in dilating strictures that are accessible, less than $5 \mathrm{~cm}$ in length, and without severe inflammatory activity, is reported for between $60 \%$ and $80 \%$ of patients and repeat endoscopic balloon dilation may be undertaken [224-226], but long-term outcomes are less well known. Perforation rates following endoscopic balloon dilation of Crohn's disease-related strictures at device-assisted enteroscopy may be as high as $9 \%[224,227-230]$. 
ESGE recognises small-bowel capsule endoscopy/device-assisted enteroscopy and magnetic resonance or computed tomography enterography/enteroclysis as complementary strategies (weak recommendation, low quality evidence).

Cost-effectiveness data regarding optimal investigation strategies for diagnosis of small-bowel Crohn's disease are lacking.

Cost-effectiveness analyses are intended to support resource allocation decisions and are therefore dependent on local/regional socioeconomic perspectives [231]. Diagnostic techniques may affect patient outcomes indirectly by influencing subsequent management strategies, implying that benefits from a specific diagnostic test depend on performance characteristics (e.g. sensitivity and specificity) as well as other factors, such as prevalence of the disease and effectiveness of available treatments [232]. In Europe alone, Crohn's disease directly results in a health care expenditure of between 4.6 to 5.6 billion euros per year. In addition to this, the indirect costs are estimated to be twice as high as the direct costs [233] and any delay in establishing the diagnosis may further increase this burden [234]. Therefore, mitigating this burden by cost-effective diagnostic and therapeutic strategies is paramount.

The use of high pre-test probability indicators in suspected small-bowel Crohn's disease, for example application of the International Conference on Capsule Endoscopy (ICCE) criteria [71] with or without appropriate use of faecal inflammatory markers [155-157,160,235], may improve allocation of limited resources, and reduce the need for more invasive and expensive diagnostic investigations in patients with a low pre-test probability. In patients with strong suspicion of Crohn's disease, ileocolonoscopy is the diagnostic method of choice for detecting colonic Crohn's disease and/or disease activity in the terminal ileum. In order to establish disease extent at first presentation, further small-bowel imaging should be included in the diagnostic workup; however the preferred, most cost-effective method for this remains unknown [236]. In about $10 \%$ of patients, Crohn's disease only affects the small bowel proximal to the terminal ileum and disease activity in these patients may not be detected by ileocolonoscopy.

In patients with a negative ileocolonoscopy, the most cost-effective diagnostic algorithm with regard to small-bowel endoscopy versus dedicated cross-sectional imaging is still debated. Costeffectiveness analysis of performing VCE immediately after ileocolonoscopy or only after dedicated small-bowel cross-sectional imaging in patients with suspected Crohn's disease has produced conflicting results [237]. Although meta-analysis suggests a higher sensitivity and optimal negative predictive value for endoscopic methods compared with radiology, transmural and extramural lesions are only detected by dedicated small-bowel crosssectional imaging [126] and the endoscopic and radiological technologies are therefore best considered to be complementary [238].

Cost-effectiveness comparisons of currently available small-bowel radiological investigations have also yielded conflicting results. Sensitivity analysis in one study suggested that in patients with a high prevalence of complications, MRE becomes as cost-effective as SBFT/small-bowel enteroclysis which although cheaper, is less accurate and may miss extramural disease while exposing patients to ionizing radiation [239]. A comparison of MRE and CTE showed that although MRE has the advantage of being radiationfree and allows dynamic evaluations of small-bowel peristalsis, it is a more expensive and longer examination with slightly inferior spatial resolution. In younger patients ( $\leq 50$ years of age), MRE is likely to reach cost-effectiveness when compared with CTE; however low dose CTE may become an alternative cost-effective choice in the future [240].

Although cost-effectiveness comparisons of algorithms involving VCE and device-assisted enteroscopy in the setting of small-bowel bleeding have shown that capsule-directed device-assisted enteroscopy appears to be the most cost-effective strategy [241, 242], similar data for VCE versus device-assisted enteroscopy in the work-up of Crohn's disease are lacking. Device-assisted enteroscopy also offers the potential for endotherapy (such as endoscopic balloon dilation of strictures) in patients with small-bowel Crohn's disease, and this may considered as a beneficial and effective alternative to surgery in selected patients [224, 229]; however, cost-effectiveness or comparative studies of endoscopic versus surgical treatment of small-bowel strictures are not available.

\section{Small-bowel tumours}

\section{$\boldsymbol{\nabla}$}

ESGE recommends early use of small-bowel video capsule endoscopy in the search for a small-bowel tumour when obscure gastrointestinal bleeding and iron-deficiency anaemia are not explained otherwise (strong recommendation, moderate quality evidence).

Most small-bowel tumours are detected during work-up for obscure gastrointestinal bleeding (OGIB) or iron-deficiency anaemia (IDA), but are the cause in only about $3.5 \%-5 \%$ of these patients [93], making these symptoms weak predictors. The clinical manifestations of small-bowel tumour, unfortunately, tend to be very nonspecific, and this can delay the diagnosis, especially in the early stages. Associated with a higher risk of small-bowel tumour are non-Hodgkin's lymphomas as follicular lymphoma, hepatic metastasis of previously undiagnosed primary neuroendocrine tumor [243-245], and stage IV malignant melanoma, or stage III malignant melanoma with positive faecal occult blood test [246]. Coeliac disease that is complicated by anaemia, that is refractory, or where there are persistent complaints despite a gluten-free diet, may be associated with T-cell lymphoma or adenocarcinoma $[247,248]$ and might represent an indication for small-bowel capsule endoscopy (VCE).

Data on small-bowel endoscopy in small-bowel tumour are often retrieved as a small part from larger mixed series; the low percentage of small-bowel tumour findings compared with other findings in OGIB makes prospective trials almost impossible. A meta-analysis showed that VCE has a significantly higher diagnostic yield compared with push-enteroscopy in patients with OGIB [14]; however, regarding the small number of tumours included, VCE showed only a nonsignificant trend towards a higher diagnostic yield than push-enteroscopy. In a highly selected group of 30 patients, from 112 patients with small-bowel tumour detected by VCE, push-enteroscopy had a diagnostic yield of $70 \%$ [249]. Thus, push-enteroscopy could represent a reliable tool for further work-up of small-bowel tumour that is clearly localized to the proximal jejunum. In OGIB patients, the diagnostic yield of VCE is similar to that of double-balloon enteroscopy (DBE) $[12,15]$ and of intraoperative enteroscopy [8]. Translating these results also to the small subgroups of patients with small-bowel 
tumour included in these studies, VCE appears to be sufficiently accurate in detecting small-bowel tumours. Of note, concordance of findings between VCE and DBE was less good in patients with small-bowel tumour than in patients with inflammatory and vascular lesions [76]. Factors associated with diagnosis of smallbowel tumour by DBE were suspected tumour at radiological or VCE investigation, or evaluation or therapy of disease as lymphoma; but not associated were presence of stenotic symptoms, gender, or age. OGIB as the indication for investigation was significantly lower in patients with small-bowel tumour diagnosed at DBE [250]. Thus, DBE might be rather applied in a highly selected group, while VCE may serve as a selection tool for patients with small-bowel tumour in the large group with OGIB.

The risk of false-negative results in VCE should be always considered, being more frequent for small-bowel tumours and polyps in the duodenum and proximal jejunum, and for submucosal masses where a mucosal component is absent, such as neuroendocrine tumours or gastrointestinal stromal tumours (GISTs) [75, $244,251-254]$.

VCE seems to be superior to small-bowel barium radiography $[14,249,255]$. Data concerning computed tomography-enterography/enteroclysis (CTE) and magnetic resonance-enterography/enteroclysis (MRE) are sparse and contradictory. MRE has been demonstrated to have high sensitivity (86\%) and specificity (98\%) for small-bowel tumours [256]. In a retrospective analysis of 77 patients, the specificity of MRE was higher than that of VCE ( 0.97 vs. $0.84, P=0.047)$, whereas the sensitivity was similar $(0.79$ vs. $0.74, P=0.591$ ) [257]. A prospective blinded comparison in 58 patients with OGIB showed similar overall diagnostic yields for multiphase CTE at 28/58 (48\%) and VCE at 25/58 (43\%). However, CTE diagnosed 9/9 small-bowel tumours, while VCE found only 3 (33\%) [35]. On the other hand, in patients with Lynch syndrome, VCE was superior to CTE in detecting small-bowel tumours, identifying one carcinoma and two adenomas, while CTE only raised suspicion of one carcinoma [258]. With specific reference to Lynch syndrome, it must be emphasized that although VCE has the potential to detect small-bowel neoplastic lesions, it may also miss these lesions [259]. Consequently, the role of VCE for surveillance of the small bowel in Lynch syndrome remains at present controversial.

Diagnosis of small-bowel tumours by VCE can be challenging. A retrospective analysis demonstrated that a proposed tumour score that took into account bleeding, mucosal disruption, an irregular surface, colour, and white villi was helpful in identifying small-bowel mass lesions [260]. A small prospective study applied a score for smooth protruding lesions, with the following criteria: ill-defined boundary with the surrounding mucosa, diameter larger than height, non-visible lumen in the frames in which the lesion appears, and an image lasting less than 10 minutes (Smooth, Protruding lesion Index on Capsule Endoscopy [SPICE] score). The score had a sensitivity of $83 \%$ and a specificity of $89 \%$; however, 2 false-positive and 1 false-negative diagnoses of small-bowel tumour were still encountered [261]. Further larger prospective studies are needed to validate such scoring systems.
In the setting of suspicion of a small-bowel tumour, ESGE does not recommend specific investigations before small-bowel capsule endoscopy in patients without evidence for stenosis or previous small-bowel resection (strong recommendation, low quality evidence).

ESGE recommends consideration of device-assisted enteroscopy in preference to small-bowel capsule endoscopy if imaging tests have already shown suspicion of small-bowel tumour (strong recommendation, low quality evidence).

Most patients with small-bowel tumour detected at VCE had the indication of OGIB or IDA [262]. It can be borne in mind that: (a) only a minority of such patients have a neoplasm [249]; (b) the retention rate in small-bowel tumour is only slightly higher than in other bleeding disorders $[142,255]$; (c) retention is in general asymptomatic [249]; and (d) most patients with small-bowel tumour will undergo surgical resection of the tumour (with the possibility of easy retrieval of a capsule). Therefore it does not seem justified to routinely perform tests to exclude stenosis before VCE in bleeding patients without clinical evidence for obstruction. Conversely, if there is already a suspicion of small-bowel tumour at imaging tests, device-assisted enteroscopy should be considered in preference to VCE, in order to avoid capsule retention and to obtain histological information.

ESGE recommends cross-sectional imaging to ascertain operability when there is a small-bowel capsule endoscopy finding of small-bowel tumour with a high diagnostic certainty. When there is uncertain diagnosis of small-bowel tumour at capsule endoscopy, biopsy sampling by device-assisted enteroscopy is required (strong recommendation, low quality evidence).

When a submucosal mass is detected by small-bowel capsule endoscopy, ESGE recommends confirmation of the diagnosis by device-assisted enteroscopy (strong recommendation, low quality evidence).

When capsule endoscopy shows high suspicion of submucosal mass and there is a negative but incomplete device-assisted enteroscopy, ESGE suggests cross-sectional imaging tests to confirm the diagnosis (weak recommendation, low quality evidence).

When there is a clear diagnosis of small-bowel tumour at VCE (ulcerated, bleeding mass lesion, stenosis) surgery without previous histological investigation seems justified. Cross-sectional imaging techniques should be requested to exclude inoperability. When protruding small-bowel lesions of uncertain nature are detected by VCE, device-assisted enteroscopy or imaging examinations are required, since innocent bulges may be confused with submucosal tumours (false-positive VCE findings). A tattoo placed during device-assisted enteroscopy may facilitate recognition of a small mass lesion at subsequent (laparoscopic) surgery [249].

Most studies on device-assisted enteroscopy and small-bowel tumours relate to DBE. Small series on single-balloon enteroscopy and spiral enteroscopy suggesting similar results need further confirmation. Device-assisted enteroscopy and VCE seem to have comparable sensitivity. A lower specificity of VCE seems to be related to the high rate of false-positive (mainly submucosal) masses. In a Chinese series, all 32 tumours detected by VCE and confirmed by DBE were further confirmed by surgery [28]; a further 6 submucosal tumours suspected at VCE were considered to 
be false-positive findings, as they were not confirmed by DBE. Two studies found that DBE was superior to computed tomography (CT) scan in the diagnosis of small-bowel tumours, including submucosal masses $[263,264]$. In a series of 12 gastrointestinal stromal tumours (GISTs), the detection rates of DBE, VCE, and CT were $92 \%, 60 \%$, and $67 \%$, respectively. All cases, except for one incomplete study, were identified using DBE. One case was not diagnosed as a tumour because of the presence of extramural growth [254]. In a study of 159 patients with small-bowel tumours, VCE and DBE had significantly higher diagnostic yields than contrast-enhanced computed tomography (CECT), and DBE had significantly higher diagnostic yields than VCE, but a combination of CECT and VCE had a diagnostic yield similar to that of DBE [265].

ESGE recommends against small-bowel capsule endoscopy in the follow-up of treated small-bowel tumours because of lack of data (strong recommendation, low quality evidence).

In patients with treated follicular lymphoma, VCE was found to detect lesions at a similar rate to DBE; however, as identification of residual lymphoma required biopsy, the authors recommend DBE for follow-up [266]. Only one of 11 patients with a VCE diagnosis of malignant small-bowel tumour who underwent surgery had recurrent bleeding; in this patient it was caused by metastasis of gastric and papillary cancer in familial adenomatous polyposis (FAP) [267]. There are no studies to support regular followup of asymptomatic patients after resection of small-bowel tumour in the absence of inherited polyposis syndromes.

\section{Inherited polyposis syndromes}

$\nabla$

\section{Familial adenomatous polyposis}

ESGE recommends that surveillance of the proximal small bowel in familial adenomatous polyposis is best performed using conventional forward-viewing and side-viewing endoscopes (strong recommendation, moderate quality evidence).

When small-bowel investigation is clinically indicated in familial adenomatous polyposis, ESGE suggests that small-bowel capsule endoscopy and/or cross-sectional imaging techniques may be considered for identifying polyps in the rest of the small bowel, but the clinical relevance of such findings remains to be demonstrated (weak recommendation, moderate quality evidence).

In familial adenomatous polyposis (FAP), the reference examination for the proximal small bowel, on account of to the high cumulative risk of severe duodenal polyposis and high relative risk of duodenal cancer, is axial- and lateral-viewing endoscopy in the same investigation [268-271]. Jejunal and ileal polyps can be found in $40 \%-70 \%$ of FAP patients; an association between the severity of duodenal polyposis and the presence of more distal small-bowel polyps has also been demonstrated [270,272274]. It is known that adenomas in the duodenum and the periampullary region are poorly identified with small-bowel video capsule endoscopy (VCE), at least with an accuracy that is inferior to that of axial-viewing endoscopy [274,275]; exact polyp size estimation is another limitation of VCE [276].

Studies comparing push-enteroscopy with VCE in FAP patients have shown conflicting results $[273,277]$, whereas systematic comparison of VCE with device-assisted enteroscopy in these patients is still warranted. VCE has demonstrated higher sensitivity for polyps than radiological investigations such as small-bowel barium studies and magnetic resonance enterography/enteroclysis (MRE) [249,273,274,278]. MRE has been shown to be more accurate than VCE in the location of bigger polyps and determination of their exact sizes [278]. The clinical relevance of detecting "distal" small-bowel polyps in FAP patients is highly uncertain the majority being lymphoid hyperplasia, without evidence for advanced adenomas [279], and also considering the low frequency of jejunal and ileal carcinomas in these patients [280].

FAP patients present with desmoid tumours in $10 \%$ of cases. Asymptomatic extensive mesenteric desmoid tumours represent a risk in this situation. Cases of acute occlusion related to VCE retention have been reported, including a case of desmoid tumour in a FAP patient $[281,282]$. Prior exclusion of intra-abdominal desmoid tumours by imaging techniques seems reasonable in FAP patients if VCE is under consideration.

Limited evidence exists concerning the use of device-assisted enteroscopy in FAP patients [283-286]. If polyps larger than $1 \mathrm{~cm}$ are identified at VCE or with cross-sectional imaging techniques, device-assisted enteroscopy is usually performed in order to obtain targeted biopsies and accomplish local endoscopic therapy [274,287]. Although it is technically feasible, the value of such an approach in these patients has yet to be demonstrated. In FAP patients with reconstruction with a Roux-en-Y anastomosis after a Whipple procedure, device-assisted enteroscopy may be useful for investigation of such anatomically altered bowel segments [288].

\section{Peutz-Jeghers syndrome}

ESGE recommends small-bowel surveillance in patients with Peutz-Jeghers syndrome. Small-bowel capsule endoscopy and/or magnetic resonance enterography/enteroclysis appear adequate methods for this purpose, depending on local availability and expertise, or patient preference (strong recommendation, moderate quality evidence).

The initial main purpose of small-bowel surveillance in Peutz-Jeghers syndrome (PJS) patients is to reduce the polyp burden and the likelihood of polyp-related complications, particularly intussusception. With advancing age, this focus may shift to the early detection of small-bowel cancer or precancerous lesions; however, the preventive effect of surveillance on development of such neoplasia remains to be proven $[289,290]$.

VCE has a greater sensitivity than small-bowel follow-through (SBFT) in detecting small-bowel polyps [291-293]. In comparison with MRE: VCE was superior at detecting small polyps; polyps $>1 \mathrm{~cm}$ were detected equally with both modalities, and location of polyps and determination of their exact sizes was more accurate with MRE [278, 294,295]. MRE was also shown to be less prone to missing large polyps than VCE [294]. A small study reported a $93 \%$ concordance between MRE and enteroscopy (i.e. double-balloon enteroscopy [DBE], laparoscopic endoscopy, or surgery) for larger (>15 mm) and more risky polyps [296]. Compared with device-assisted enteroscopy, VCE has the advantage of allowing a more complete examination of the small bowel in 
PJS patients; however false-negative results may occur with VCE $[297,298]$. In a retrospective multicentre study, 25 patients underwent VCE followed by consecutive DBE when treatment was indicated. Authors found a strong agreement for polyp location and size, but not for number of polyps; device-assisted enteroscopy was more accurate for the latter [299].

The PillCam patency capsule test may be considered before VCE in PJS patients with history of prior small-bowel resection, as it has been shown to be useful in detection of relevant stenosis $[144,300]$.

\section{ESGE recommends device-assisted enteroscopy with timely poly- pectomy when large polyps $(>10-15 \mathrm{~mm})$ are discovered by ra- diological examination or small-bowel capsule endoscopy in pa- tients with Peutz-Jeghers syndrome (strong recommendation, moderate quality evidence).}

It is now well acknowledged that polyp size is the most important risk factor for small-bowel intussusception with intestinal obstruction, and that intussusception is generally due to polyps $\geq 15 \mathrm{~mm}$ in diameter [301-303]. Consequently, large polyps $(10-15 \mathrm{~mm})$ or symptomatic or rapidly growing polyps should be removed. Device-assisted enteroscopy is clinically useful for diagnosis and relatively safe for therapy of small-bowel polyps in PJS patients, both in adults and in children [286,301,304308].

A study described 29 diagnostic and therapeutic DBE procedures in 13 patients with PJS, with removal of multiple polyps $>1 \mathrm{~cm}$ [304] without complications. However, two other studies, report a complication rate of up to $6.8 \%$, including acute pancreatitis (2.7\%) [306] and post-polypectomy syndrome (5\%) [305].

In PJS, completeness of small-bowel investigation by device-assisted enteroscopy may be jeopardized by previous laparotomies [303]. If there is no information on polyp burden, from the age of 8 - 10 years [289,290,302,309], an initial VCE/MRE may be preferred to select for device-assisted enteroscopy only those patients with a need for therapy. When there is a high polyp burden, and incomplete polypectomy during a device-assisted enteroscopy, the next surveillance might preferably also be done by device-assisted enteroscopy, as this is more cost-effective in a setting where a high proportion of procedures are therapeutic. Indeed, repeated DBE examinations have been reported to reduce small-bowel polyp burden and to prevent polyp-related complications such as intussusception [304-306]. When a polyp is too large for safe removal with device-assisted enteroscopy or cannot be reached using this modality, intraoperative enteroscopy could be considered for polypectomy or enterotomy.

\section{Coeliac disease}

$\nabla$

\section{ESGE strongly recommends against the use of small-bowel capsule endoscopy for suspected coeliac disease but suggests that capsule endoscopy could be used in patients unwilling or unable to undergo conventional endoscopy (strong recom- mendation, low quality evidence).}

Coeliac disease is a common autoimmune condition characterized by a heightened immunological response to ingested gluten, with prevalence rates in the United States and European popula- tions estimated to range between $0.2 \%$ and $1 \%$ [310,311]. The current gold standard diagnostic test for coeliac disease is oesophagogastroduodenoscopy (OGD) with duodenal biopsies and small-bowel histology demonstrating the presence of villous atrophy (Marsh stage 3a to 3c) [312]. Corroborative evidence used to support the diagnosis of coeliac disease comes from positive serological tests (tissue transglutaminase [tTG] and endomysial antibodies [EMA]) and a clinical response to a gluten-free diet. Occasionally when diagnostic uncertainty exists, human leucocyte antigen (HLA) typing is undertaken which may help to exclude coeliac disease, given the high negative predictive value of this test.

OGD has several potential limitations as part of this diagnostic pathway. These include its invasive nature and the inability to evaluate small-bowel mucosa beyond the duodenum. Changes shown in coeliac disease are well-recognised to be patchy [313], and occasionally in some patients the small bowel distal to the reach of a standard gastroscope may be more affected than the proximal bowel where biopsies are taken [314-316]. There has been increasing interest in the role small-bowel video capsule endoscopy (VCE) may have in coeliac disease. With 8-fold magnification power comparable to that of a dissecting microscope, VCE has the potential to detect villous atrophy and other smallbowel complications seen in coeliac disease.

Studies assessing the utility of VCE in diagnosing coeliac disease have reported the following diagnostic values for VCE: sensitivity $70 \%-100 \%$ : specificity $64 \%-100 \%$; positive predictive value (PPV) 96\% - 100\%; and negative predictive value (NPV) 71\%-93\% $[314,317-320]$. A consistent finding in all of these studies is that, in the presence of EMA or significantly elevated tTG, the PPV and specificity for the recognition of endoscopic markers of coeliac disease are $100 \%$. However, the high pre-test probability of coeliac disease in all of these studies may again be a potential limitation leading to an overestimation of VCE performance. Nevertheless, they accurately reflect real-life clinical practice where patients are likely to be selected for VCE of the basis of positive serological results, and suggest that VCE may be an appropriate tool for patients who are unable to undergo OGD.

ESGE recommends that there is no role for small-bowel capsule endoscopy in assessing the extent of disease or response to a gluten-free diet (strong recommendation, low quality evidence).

One area where VCE may confer an advantage over standard endoscopy is that VCE has the potential to image the entire small bowel. Intuitively it would seem that the more of the bowel that is affected, the more severe the symptoms and the higher the chance of potential complications. However this has not been proven, mainly because it is difficult to assess the extent of disease. VCE may provide a way of doing this. In a study of 38 patients with untreated coeliac disease and 38 controls [314], the authors were unable to show a relationship between either qualitative or quantitative assessments of extent of disease and severity of clinical presentation; however a positive EMA result was associated with more extensive disease. In the 30 coeliac disease patients who agreed to repeat VCE after adopting a glutenfree diet, the mean time in which abnormality was observed reduced from 60 minutes to 12 minutes. A second more recent study of 12 patients with coeliac disease who had repeat VCE after 12 months on a gluten-free diet has also demonstrated such an improvement [319]. Although there was no initial corre- 
lation between extent of disease and clinical severity, they did demonstrate a significant reduction in the mean time in which villous atrophy was observed. On the evidence of these two studies, so far no relationship between extent of small-bowel involvement and clinical severity of disease has been demonstrated. As experience with VCE in coeliac disease increases, however, such a demonstration may become possible.

ESGE suggests the use of small-bowel capsule endoscopy in cases of equivocal diagnosis of coeliac disease (weak recommendation, low quality evidence).

Another area where VCE may play a role is in the investigation of cases with equivocal diagnosis of coeliac disease. The changes of coeliac disease can be patchy and a duodenal biopsy in patients with positive serological findings might not demonstrate villous atrophy. Lesser degrees of histological abnormality that can be associated with coeliac disease are nonspecific and are seen in a variety of other conditions. This can leave some patients without a definitive diagnosis. In a study of 8 patients with positive serological results (EMA or tTG) and normal findings from duodenal biopsy, VCE did not reveal any endoscopic features of coeliac disease [319]. Thus the investigators concluded that there was no benefit in performing VCE for this subgroup of patients; another similar study came to the same conclusions [321]. There is however conflicting evidence. In a further study of 30 patients by Kurien et al. with Marsh stage 1 or 2 changes, only 6 of whom had positive EMA or tTG results, one patient was diagnosed with coeliac disease and another with small-bowel Crohn's disease on the basis of VCE appearances [322]. It is clear that further work is required to assess the cost-effectiveness of the use of VCE in these equivocal cases if the yield is as low as in the study by Kurien et al. VCE use may be justified however, in patients who are positive for EMA or tTG positive patients who have Marsh stage 1 or 2 changes or gastrointestinal symptoms, particularly if they are unwilling to undergo further OGD and repeat biopsies.

Patients with antibody-negative villous atrophy represent another diagnostic challenge since there is a wide range of differential diagnoses for villous atrophy. In the study of equivocal cases by Kurien et al. [322] they also included a group of patients with antibody-negative villous atrophy to see whether this increased the diagnostic yield. Patients were extensively investigated for coeliac disease including human leukocyte antigen (HLA) phenotyping, by monitoring their response to a gluten-free diet and, in some cases, repeat duodenal biopsies. On the basis of VCE appearances and other ancillary tests, 7 patients could be diagnosed with coeliac disease and 2 further patients were diagnosed with small-bowel Crohn's disease as a cause for villous atrophy. Again this is a single small study and further work needs to be done to clarify the role of VCE in antibody-negative villous atrophy cases. This is particularly important as VCE alone is probably insufficient to confirm a diagnosis of coeliac disease, given that endoscopic markers are not specific to coeliac disease and are, rather, predictors of mucosal disease [323].
ESGE recommends initial assessment by small-bowel capsule endoscopy followed by device-assisted enteroscopy in nonresponsive or refractory coeliac disease (strong recommendation, low quality evidence).

The distribution of serious complications of coeliac disease such as refractory coeliac disease and enteropathy-associated T-cell lymphomas (EATLs) is particularly important as these appear to be more commonly seen in the distal small bowel [324-328]. Ulcerative jejunitis is usually associated with refractory coeliac disease type II and with a high risk of developing EATL. Early identification of refractory coeliac disease type II may allow effective treatment with immunosuppression and prevent progression to EATL. VCE could therefore play a role in the investigation of these patients. In two studies of patients with coeliac disease and persisting symptoms, a few serious complications were identified by VCE including cases of EATL, ulcerative jejunitis, and refractory coeliac disease types I and II, some of which were confirmed by double-balloon enteroscopy (DBE) and biopsy [322, 325].

The use of VCE to assess the extent and severity of disease in patients with known refractory coeliac disease may also be helpful, as shown in a recent study of 29 patients with refractory coeliac disease and 9 patients with symptomatic coeliac disease [248]. In the refractory coeliac disease cohort, 3 cases of EATL were identified and 5 cases of ulcerative jejunitis requiring specific treatment. The majority of the refractory coeliac disease patients also underwent device-assisted enteroscopy and the authors concluded that, on the basis of VCE findings, 17 patients could have avoided this invasive investigation. Apart from the latter study [248], where there was an unusually high proportion of patients with refractory coeliac disease, the apparent diagnostic yield for complications such as EATL and ulcerative jejunitis appears low. However these diagnoses carry significant rates of morbidity and mortality which may be reduced by prompt diagnosis. The use of capsule endoscopy followed by device-assisted enteroscopy $[329,330]$ in patients with nonresponsive disease may therefore be justified.

Patients with ulcerative jejunitis and EATL can have a significant risk of small-bowel stricturing. VCE should be used with caution therefore and a patency capsule should always be employed to reduce the incidence of capsule retention.

Magnetic resonance enteroclysis has also been suggested for the detection of malignancies related to coeliac disease [331].

ESGE guidelines represent a consensus of best practice based on the available evidence at the time of preparation. They may not apply in all situations and should be interpreted in the light of specific clinical situations and resource availability. Further controlled clinical studies may be needed to clarify aspects of these statements, and revision may be necessary as new data appear. Clinical consideration may justify a course of action at variance to these recommendations. ESGE guidelines are intended to be an educational device to provide information that may assist endoscopists in providing care to patients. They are not rules and should not be construed as establishing a legal standard of care or as encouraging, advocating, requiring, or discouraging any particular treatment. 
Competing interests: J. Albert, research funding from Covidien (formerly Given Imaging); J. P. Charton, speaker for Covidien; R. Eliakim, paid consultant for Covidien; I. Gralnek, paid consultant for and research funding from Covidien; M. McAlindon, co-director of CapsuleReader Ltd; M. Pennazio, speaker for Covidien.

\section{Institutions}

${ }^{1}$ Division of Gastroenterology, San Giovanni Battista University Teaching Hospital, Turin, Italy

2 Digestive Endoscopy Unit, Catholic University, Rome, Italy

3 Department of Gastroenterology, Chaim Sheba Medical Center, Sackler

School of Medicine, Tel-Aviv University Tel-Hashomer, Israel

${ }^{4}$ Klinik für Innere Medizin, Bethesda Krankenhaus Bergedorf, Hamburg, Germany

${ }^{5}$ Department of Medicine II, Sana Klinikum, Offenbach, Germany

${ }^{6}$ Department of Gastroenterology and Hepatology, VU University Medical Centre, Amsterdam, The Netherlands

${ }^{7}$ Gastroenterology Unit, Ospedale Valduce, Como, Italy

${ }^{8}$ Division of Gastroenterology, Shaare Zedek Medical Center, Jerusalem, Israel

${ }^{9}$ Department of Medicine I, Johann Wolfgang Goethe University Frankfurt, Frankfurt, Germany

${ }^{10}$ Assistance Publique-Hôpitaux de Paris, Hôpital Européen Georges-Pompidou, Service d'Hépato-gastro-entérologie, Paris, France

${ }^{11}$ Medizinische Klinik, Evangelisches Krankenhaus, Düsseldorf, Germany

12 Department of Hepato-Gastroenterology, Nouvel Hôpital Civil, University Hospital of Strasbourg, Strasbourg, France

${ }^{13}$ Royal Free Unit for Endoscopy and Centre for Gastroenterology, The Royal Free Hospital and University College London, London, UK

${ }^{14}$ Department of Medicine B, University of Münster, Münster, Germany

15 Institute of Gastroenterology and Liver Diseases, Ha'emek Medical Center

Afula, Israel, Rappaport Faculty of Medicine, Technion-Israel Institute of Technology Haifa, Israel

${ }^{16}$ Department of Gastroenterology, Royal Hallamshire Hospital, Sheffield Teaching Hospitals NHS Foundation Trust, Sheffield, UK

${ }^{17}$ Gastroenterology Department, Centro Hospitalar do Alto Ave, Guimarães, Portugal.

${ }^{18}$ Clinical Psychology Unit, Department of Psychology, University of Sheffield.

${ }^{19}$ Centre Hospitalier Lyon Sud, Pierre Bénite, Lyon, France

${ }^{20}$ Gedyt Endoscopy Center, Buenos Aires, Argentina

${ }^{21}$ Department of Gastroenterology, Nuovo Regina Margherita Hospital, Rome, Italy

\section{References}

1 Rey JF, Ladas S, Alhassani A et al. ESGE Guidelines Committee. European Society of Gastrointestinal Endoscopy (ESGE). Video capsule endoscopy: update to guidelines (May 2006). Endoscopy 2006; 38: $1047-1053$

2 Ladas SD, Triantafyllou K, Spada C et al. ESGE Clinical Guidelines Committee. European Society of Gastrointestinal Endoscopy (ESGE): recommendations (2009) on clinical use of video capsule endoscopy to investigate small-bowel, esophageal and colonic diseases. Endoscopy 2010; 42: 220-227

3 Atkins $D$, Best D, Briss PA et al. Grading quality of evidence and strength of recommendations. BMJ 2004; 328: 1490

4 Dumonceau JM, Hassan C, Riphaus A et al. European Society of Gastrointestinal Endoscopy (ESGE) Guideline Development Policy. Endoscopy 2012; 44: 626-629

5 Raju GS, Gerson L, Das A et al. American Gastroenterological Association (AGA) Institute medical position statement on obscure gastrointestinal bleeding. Gastroenterology 2007; 133: 1694-1696

6 Fisher L, Lee KM, Anderson MA et al. The role of endoscopy in the management of obscure GI bleeding. Gastrointest Endosc 2010; 72: 471 479

7 Bonnet S, Douard R, Malamut G et al. Intraoperative enteroscopy in the management of obscure gastrointestinal bleeding. Dig Liver Dis 2013; 45: $277-284$

8 Hartmann D, Schmidt $H$, Bolz $G$ et al. A prospective two-center study comparing wireless capsule endoscopy with intraoperative enteroscopy in patients with obscure GI bleeding. Gastrointest Endosc 2005; 61: $826-832$

9 Tenembaum D, Sison C, Rubin M. Accuracy of community based video capsule endoscopy in patients undergoing follow up double balloon enteroscopy. World J Gastrointest Endosc 2013; 5: 154-159

10 Pennazio $M$, Santucci $R$, Rondonotti $E$ et al. Outcome of patients with obscure gastrointestinal bleeding after capsule endoscopy: report of 100 consecutive cases. Gastroenterology 2004; 126: 643-653
11 Shishido T, Oka S, Tanaka S et al. Diagnostic yield of capsule endoscopy vs. double-balloon endoscopy for patients who have undergone total\# enteroscopy with obscure gastrointestinal bleeding. Hepatogastroenterology 2012; 59: 955 -959

12 Teshima CW, Kuipers EJ, van Zanten SV et al. Double balloon enteroscopy and capsule endoscopy for obscure gastrointestinal bleeding: an updated meta-analysis. J Gastroenterol Hepatol 2011; 26: 796801

13 Liao Z, Gao $R, X u C$ et al. Indications and detection, completion, and retention rates of small-bowel capsule endoscopy: a systematic review. Gastrointest Endosc 2010; 71: 280 - 286

14 Triester SL, Leighton JA, Leontiadis GI et al. A meta-analysis of the yield of capsule endoscopy compared to other diagnostic modalities in patients with obscure gastrointestinal bleeding. Am J Gastroenterol 2005; 100: 2407 - 2418

15 Pasha SF, Leighton JA, Das A et al. Double-balloon enteroscopy and capsule endoscopy have comparable diagnostic yield in small-bowel disease: a meta-analysis. Clin Gastroenterol Hepatol 2008; 6: 671 676

16 Chen X, Ran ZH, Tong JL. A meta-analysis of the yield of capsule endoscopy compared to double-balloon enteroscopy in patients with small bowel diseases. World J Gastroenterol 2007; 13: 4372 - 4378

17 Lepileur L, Dray X, Antonietti $M$ et al. Factors associated with diagnosis of obscure gastrointestinal bleeding by video capsule enteroscopy. Clin Gastroenterol Hepatol 2012; 10: 1376-1380

18 Carey EJ, Leighton JA, Heigh RI et al. A single-center experience of 260 consecutive patients undergoing capsule endoscopy for obscure gastrointestinal bleeding. Am J Gastroenterol 2007; 102: 89-95

19 Sidhu R, Sanders DS, Kapur K et al. Factors predicting the diagnostic yield and intervention in obscure gastrointestinal bleeding investigated using capsule endoscopy. J Gastrointest Liver Dis 2009; 18: $273-278$

20 Shahidi NC, Ou G, Svarta S et al. Factors associated with positive findings from capsule endoscopy in patients with obscure gastrointestinal bleeding. Clin Gastroenterol Hepatol 2012; 10: 1381 - 1385

21 Katsinelos P, Chatzimavroudis $G$, Terzoudis $S$ et al. Diagnostic yield and clinical impact of capsule endoscopy in obscure gastrointestinal bleeding during routine clinical practice: a single-center experience. Med Princ Pract 2011; 20: 60-65

22 Bresci G, Parisi G, Bertoni $M$ et al. The role of video capsule endoscopy for evaluating obscure gastrointestinal bleeding: usefulness of early use. J Gastroenterol 2005; 40: 256-259

23 Singh A, Marshall C, Chaudhuri B et al. Timing of video capsule endoscopy relative to overt obscure GI bleeding: implications from a retrospective study. Gastrointest Endosc 2013; 77: 761 - 766

24 Leighton JA, Triester SL, Sharma VK. Capsule endoscopy: a meta-analysis for use with obscure gastrointestinal bleeding and Crohn's disease. Gastrointest Endosc Clin N Am 2006; 16: 229-250

25 de Leusse A, Vahedi K, Edery J et al. Capsule endoscopy or push enteroscopy for first-line exploration of obscure gastrointestinal bleeding? Gastroenterology 2007; 132: 855-862

26 Shim KN, Moon JS, Chang DK et al. Guideline for capsule endoscopy: obscure gastrointestinal bleeding. Clin Endosc 2013; 46: 45 - 53

27 Gay G, Delvaux M, Fassler I. Outcome of capsule endoscopy in determining indication and route for push-and-pull enteroscopy. Endoscopy 2006; 38: $49-58$

$28 \mathrm{Li} \mathrm{X}$, Chen H, Dai J et al. Predictive role of capsule endoscopy on the insertion route of double-balloon enteroscopy. Endoscopy 2009; 41: $762-766$

29 Laine L, Sahota A, Shah A. Does capsule endoscopy improve outcomes in obscure gastrointestinal bleeding? Randomized trial versus dedicated small bowel radiography Gastroenterology 2010; 138: 1673 1680

30 Leung WK, Ho SS, Suen BY et al. Capsule endoscopy or angiography in patients with acute overt obscure gastrointestinal bleeding: a prospective randomized study with long-term follow-up. Am J Gastroenterol 2012; 107: 1370-1376

31 Saperas E, Dot J, Videla $S$ et al. Capsule endoscopy versus computed tomographic or standard angiography for the diagnosis of obscure gastrointestinal bleeding. Am J Gastroenterol 2007; 102: 731 - 737

32 Agrawal JR, Travis AC, Mortele KJ et al. Diagnostic yield of dual-phase computed tomography enterography in patients with obscure gastrointestinal bleeding and a non-diagnostic capsule endoscopy. J Gastroenterol Hepatol 2012; 27: 751 - 759 
33 Zhang BL, Jiang $L L$, Chen CX et al. Diagnosis of obscure gastrointestinal hemorrhage with capsule endoscopy in combination with multipledetector computed tomography. J Gastroenterol Hepatol 2010; 25: $75-79$

34 Hara AK, Leighton JA, Sharma VK et al. Small bowel: preliminary comparison of capsule endoscopy with barium study and CT. Radiology 2004; 230: 260 - 265

35 Huprich JE, Fletcher JG, Fidler JL et al. Prospective blinded comparison of wireless capsule endoscopy and multiphase CT enterography in obscure gastrointestinal bleeding. Radiology 2011; 260: 744-751

36 Rajesh A, Sandrasegaran K, Jennings SG et al. Comparison of capsule endoscopy with enteroclysis in the investigation of small bowel disease. Abdom Imaging 2009; 34: 459-466

37 Khalife S, Soyer P, Alatawi A et al. Obscure gastrointestinal bleeding: preliminary comparison of 64-section CT enteroclysis with video capsule endoscopy. Eur Radiol 2011; 21: 79-86

38 Voderholzer WA, Ortner M, Rogalla P et al. Diagnostic yield of wireless capsule enteroscopy in comparison with computed tomography enteroclysis. Endoscopy 2003; 35: 1009 - 1014

39 Wiarda BM, Heine DG, Mensink P et al. Comparison of magnetic resonance enteroclysis and capsule endoscopy with balloon-assisted enteroscopy in patients with obscure gastrointestinal bleeding. Endoscopy 2012; 44: 668-673

40 Tanaka S, Mitsui K, Yamada Yet al. Diagnostic yield of double-balloon endoscopy in patients with obscure GI bleeding. Gastrointest Endosc 2008; 68: $683-691$

41 Sidhu R, McAlindon ME, Kapur K et al. Push enteroscopy in the era of capsule endoscopy. J Clin Gastroenterol 2008; 42: 54-58

42 Raju GS, Gerson L, Das A et al. American Gastroenterological Association (AGA) Institute technical review on obscure gastrointestinal bleeding. Gastroenterology 2007; 133: 1697-1717

43 Pennazio M, Arrigoni A, Risio $M$ et al. Clinical evaluation of push-type enteroscopy. Endoscopy 1995; 27: 164-170

44 Jeon SR, Kim JO. Deep enteroscopy: which technique will survive? Clin Endosc 2013; 46: 480-485

45 Lenz P, Roggel M, Domagk D. Double- vs. single-balloon enteroscopy: single center experience with emphasis on procedural performance. Int J Colorectal Dis 2013; 28: 1239-1246

46 Messer I, May A, Manner $H$ et al. Prospective, randomized, single-center trial comparing double-balloon enteroscopy and spiral enteroscopy in patients with suspected small-bowel disorders. Gastrointest Endosc 2013; 77: 241 - 249

47 Domagk D, Mensink P, Aktas H et al. Single- vs. double-balloon enteroscopy in small-bowel diagnostics: a randomized multicenter trial. Endoscopy 2011; 43: 472-476

48 May A, Farber M, Aschmoneit I et al. Prospective multicenter trial comparing push-and-pull enteroscopy with the single- and doubleballoon techniques in patients with small-bowel disorders. Am J Gastroenterol 2010; 105: 575-581

49 May A, Nachbar L, Schneider $M$ et al. Prospective comparison of push enteroscopy and push-and-pull enteroscopy in patients with suspected small-bowel bleeding. Am J Gastroenterol 2006; 101: 2016 2024

50 Matsumoto T, Moriyama T, Esaki M et al. Performance of antegrade double-balloon enteroscopy: comparison with push enteroscopy. Gastrointest Endosc 2005; 62: 392 - 398

51 Parry SD, Welfare MR, Cobden I et al. Push enteroscopy in a UK district general hospital: experience of 51 cases over 2 years. Eur J Gastroenterol Hepatol 2002; 14: 305 - 309

52 Tee HP, Kaffes AJ. Non-small-bowel lesions encountered during double-balloon enteroscopy performed for obscure gastrointestinal bleeding. World J Gastroenterol 2010; 16: 1885-1889

53 Wang Z, Chen JQ Liu JL et al. CT enterography in obscure gastrointestinal bleeding: a systematic review and meta-analysis. J Med Imaging Radiat Oncol 2013; 57: 263-273

54 Chen $\mathrm{LH}$, Cao HJ, Zhang $\mathrm{H}$ et al. [Diagnostic values of double-balloon enteroscopy and abdominal computed tomography in small bowel disease]. Zhonghua Yi Xue Za Zhi 2008; 88: 3305-3308

55 Yen HH, Chen YY, Yang CW et al. Clinical impact of multidetector computed tomography before double-balloon enteroscopy for obscure gastrointestinal bleeding. World J Gastroenterol 2012; 18: 692 - 697

56 Monkemuller K, Neumann $H$, Meyer $F$ et al. A retrospective analysis of emergency double-balloon enteroscopy for small-bowel bleeding. Endoscopy 2009; 41: 715-717
57 Yoon W, Jeong YY, Shin SS et al. Acute massive gastrointestinal bleeding: detection and localization with arterial phase multi-detector row helical CT. Radiology 2006; 239: 160 - 167

58 Shinozaki S, Yamamoto H, Yano T et al. Long-term outcome of patients with obscure gastrointestinal bleeding investigated by double-balloon endoscopy. Clin Gastroenterol Hepatol 2010; 8: 151 -158

59 Neu B, Ell C, May A et al. Capsule endoscopy versus standard tests in influencing management of obscure digestive bleeding: results from a German multicenter trial. Am J Gastroenterol 2005; 100: 17361742

60 Almeida N, Figueiredo $P$, Lopes $S$ et al. Urgent capsule endoscopy is useful in severe obscure-overt gastrointestinal bleeding. Dig Endosc 2009; 21: 87-92

61 Lecleire S, Iwanicki-Caron I, Di-Fiore A et al. Yield and impact of emergency capsule enteroscopy in severe obscure-overt gastrointestinal bleeding. Endoscopy 2012; 44: 337-342

62 Aniwan S, Viriyautsahakul V, Rerknimitr $R$ et al. Urgent double balloon endoscopy provides higher yields than non-urgent double balloon endoscopy in overt obscure gastrointestinal bleeding. Endoscopy International Open 2014; 02: E90-E95

63 Pérez-Cuadrado Robles E, Bebia Conesa P, Esteban Delgado $P$ et al Emergency double-balloon enteroscopy combined with real-time viewing of capsule endoscopy: A feasible combined approach in acute overt-obscure gastrointestinal bleeding? Dig Endosc 2014 Sep 23. DOI 10.1111/den.12384, Epub ahead of print

64 Selby $W$. Can clinical features predict the likelihood of finding abnormalities when using capsule endoscopy in patients with GI bleeding of obscure origin? Gastrointest Endosc 2004; 59: 782 - 787

65 Gilbert D, O'Malley S, Selby W. Are repeat upper gastrointestinal endoscopy and colonoscopy necessary within six months of capsule endoscopy in patients with obscure gastrointestinal bleeding? J Gastroenterol Hepatol 2008; 23: 1806-1809

66 Vlachogiannakos J, Papaxoinis K, Viazis N et al. Bleeding lesions within reach of conventional endoscopy in capsule endoscopy examinations for obscure gastrointestinal bleeding: is repeating endoscopy economically feasible? Dig Dis Sci 2011; 56: 1763-1768

67 Lai LH, Wong GL, Chow DK et al. Long-term follow-up of patients with obscure gastrointestinal bleeding after negative capsule endoscopy. Am J Gastroenterol 2006; 101: 1224-1228

68 Macdonald J, Porter V, McNamara D. Negative capsule endoscopy in patients with obscure GI bleeding predicts low rebleeding rates. Gastrointest Endosc 2008; 68: 1122 - 1127

69 Min YW, Kim JS, Jeon SW et al. Long-term outcome of capsule endoscopy in obscure gastrointestinal bleeding: a nationwide analysis Endoscopy 2014; 46: 59-65

70 Park JJ, Cheon JH, Kim HM et al. Negative capsule endoscopy without subsequent enteroscopy does not predict lower long-term rebleeding rates in patients with obscure GI bleeding. Gastrointest Endosc 2010; 71: $990-997$

71 Mergener K, Ponchon T, Gralnek I et al. Literature review and recommendations for clinical application of small-bowel capsule endoscopy, based on a panel discussion by international experts. Consensus statements for small-bowel capsule endoscopy, 2006/2007. Endoscopy 2007; 39: 895-909

72 Rondonotti E, Marmo R, Petracchini M et al. The American Society for Gastrointestinal Endoscopy (ASGE) diagnostic algorithm for obscure gastrointestinal bleeding: eight burning questions from everyday clinical practice. Dig Liver Dis 2013; 45: 179-185

73 Viazis N, Papaxoinis K, Vlachogiannakos J et al. Is there a role for second-look capsule endoscopy in patients with obscure GI bleeding after a nondiagnostic first test? Gastrointest Endosc 2009; 69: 850 856

74 Chong AK, Chin BW, Meredith CG. Clinically significant small-bowel pathology identified by double-balloon enteroscopy but missed by capsule endoscopy. Gastrointest Endosc 2006; 64: 445 - 449

$75 \mathrm{Li} \mathrm{X}$, Dai J, Lu H et al. A prospective study on evaluating the diagnostic yield of video capsule endoscopy followed by directed double-balloon enteroscopy in patients with obscure gastrointestinal bleeding. Dig Dis Sci 2010; 55: 1704 - 1710

76 Marmo R, Rotondano G, Casetti $T$ et al. Degree of concordance between double-balloon enteroscopy and capsule endoscopy in obscure gastrointestinal bleeding: a multicenter study. Endoscopy 2009; 41: $587-592$

77 Williamson JB, Judah JR, Gaidos JK et al. Prospective evaluation of the long-term outcomes after deep small-bowel spiral enteroscopy in pa- 
tients with obscure GI bleeding. Gastrointest Endosc 2012; 76: 771 778

78 Gerson LB, Batenic MA, Newsom SL et al. Long-term outcomes after double-balloon enteroscopy for obscure gastrointestinal bleeding. Clin Gastroenterol Hepatol 2009; 7: 664-669

79 May A, Friesing-Sosnik T, Manner $H$ et al. Long-term outcome after argon plasma coagulation of small-bowel lesions using double-balloon enteroscopy in patients with mid-gastrointestinal bleeding. Endoscopy 2011; 43: $759-765$

80 Shinozaki S, Yamamoto H, Yano T et al. Favorable long-term outcomes of repeat endotherapy for small-intestine vascular lesions by doubleballoon endoscopy. Gastrointest Endosc 2014; 80: 112 - 117

81 Rahmi G, Samaha E, Vahedi K et al. Long-term follow-up of patients undergoing capsule and double-balloon enteroscopy for identification and treatment of small-bowel vascular lesions: a prospective multicenter study. Endoscopy 2014; 46: 591 - 597

82 Goddard AF, James MW, McIntyre AS et al. Guidelines for the management of iron deficiency anaemia. Gut 2011; 60: 1309-1316

83 Riccioni ME, Urgesi R, Spada C et al. Unexplained iron deficiency anaemia: Is it worthwhile to perform capsule endoscopy? Dig Liver Dis 2010; 42: $560-566$

84 Milano A, Balatsinou C, Filippone A et al. A prospective evaluation of iron deficiency anemia in the GI endoscopy setting: role of standard endoscopy, videocapsule endoscopy, and CT-enteroclysis. Gastrointest Endosc 2011; 73: 1002 - 1008

85 Yamada A, Watabe H, Yamaji Y et al. Incidence of small intestinal lesions in patients with iron deficiency anemia. Hepatogastroenterology 2011 ; 58 : 1240 - 1243

86 Holleran GE, Barry SA, Thornton OJ et al. The use of small bowel capsule endoscopy in iron deficiency anaemia: low impact on outcome in the medium term despite high diagnostic yield. Eur J Gastroenterol Hepatol 2013; 25: $327-332$

87 Van Turenhout ST, Jacobs MA, Van Weyenberg SJ et al. Diagnostic yield of capsule endoscopy in a tertiary hospital in patients with obscure gastrointestinal bleeding. J Gastrointestin Liver Dis 2010; 19: 141 145

88 Tong J, Svarta S, Ou G et al. Diagnostic yield of capsule endoscopy in the setting of iron deficiency anemia without evidence of gastrointestinal bleeding. Can J Gastroenterol 2012; 26: 687-690

89 Sheibani S, Levesque BG, Friedland S et al. Long-term impact of capsule endoscopy in patients referred for iron-deficiency anemia. Dig Dis Sci 2010; 55: $703-708$

90 Bain GH, Ritchie VFP, Salunche SS et al. The use of small bowel capsule endoscopy in the investigation of iron deficiency anaemia. Adherence to BSG guidelines and impact on diagnostic yield. United European Gastroenterol J 2014; 02: A217

91 Efthymiou M, Allen PB, Jayasekera $C$ et al. Value of fecal occult blood test as a screening test before capsule endoscopy. Eur J Gastroenterol Hepatol 2011; 23: $690-694$

92 Kobayashi $Y$, Watabe H, Yamada A et al. Impact of fecal occult blood on obscure gastrointestinal bleeding: Observational study. World J Gastroenterol 2015; 21: 326-332

93 Koulaouzidis A, Rondonotti E, Giannakou A et al. Diagnostic yield of small-bowel capsule endoscopy in patients with iron-deficiency anemia: a systematic review. Gastrointest Endosc 2012; 76: 983 - 992

94 Apostolopoulos P, Liatsos C, Gralnek IM et al. The role of wireless capsule endoscopy in investigating unexplained iron deficiency anemia after negative endoscopic evaluation of the upper and lower gastrointestinal tract. Endoscopy 2006; 38: 1127-1132

95 Sidhu PS, McAlindon ME, Drew K et al. Diagnostic yield of small-bowel capsule endoscopy in patients with iron deficiency anemia: does it affect management? Gastrointest Endosc 2013; 78: 800 - 801

96 Koulaouzidis A, Yung DE, Lam JH et al. The use of small-bowel capsule endoscopy in iron-deficiency anemia alone; be aware of the young anemic patient. Scand J Gastroenterol 2012; 47: 1094-1100

97 Sidhu $R$, McAlindon ME, Drew $K$ et al. Evaluating the role of smallbowel endoscopy in clinical practice: the largest single-centre experience. Eur J Gastroenterol Hepatol 2012; 24: 513 - 519

98 Zuckerman GR, Prakash C, Askin MP et al. AGA technical review on the evaluation and management of occult and obscure gastrointestinal bleeding. Gastroenterology 2000; 118: 201 - 221

99 Gomez Rodriguez BJ, Ortiz MC, Romero CR et al. Diagnostic yield of 335 push video-enteroscopies. Rev Esp Enferm Dig 2006; 98: 82 - 92
100 Van Gossum A, Hittelet A, Schmit A et al. A prospective comparative study of push and wireless-capsule enteroscopy in patients with obscure digestive bleeding. Acta Gastroenterol Belg 2003; 66: 199-205

101 Keizman D, Brill S, Umansky $M$ et al. Diagnostic yield of routine push enteroscopy with a graded-stiffness enteroscope without overtube. Gastrointest Endosc 2003; 57: 877-881

102 Bezet A, Cuillerier E, Landi B et al. Clinical impact of push enteroscopy in patients with gastrointestinal bleeding of unknown origin. Clin Gastroenterol Hepatol 2004; 2: 921 -927

103 Linder J, Cheruvattath $R$, Truss $C$ et al. Diagnostic yield and clinical implications of push enteroscopy: results from a nonspecialized center.J Clin Gastroenterol 2002; 35: 383 - 386

104 Chak A, Cooper GS, Canto MI et al. Enteroscopy for the initial evaluation of iron deficiency. Gastrointest Endosc 1998; 47: 144-148

105 Manabe N, Tanaka S, Fukumoto A et al. Double-balloon enteroscopy in patients with GI bleeding of obscure origin. Gastrointest Endosc 2006; 64: 135 - 140

106 Soyer $P$. Obscure gastrointestinal bleeding: difficulties in comparing CT enterography and video capsule endoscopy. Eur Radiol 2012; 22: $1167-1171$

107 Sidhu PS, McAlindon M, Drew K et al. The utility of capsule endoscopy in patients with iron deficiency anaemia under 50 years - is the juice worth the squeeze? Gut 2013; 62 Suppl 1: A287

108 Van Weyenberg SJ, Van Turenhout ST, Jacobs MA et al. Video capsule endoscopy for previous overt obscure gastrointestinal bleeding in patients using anti-thrombotic drugs. Dig Endosc 2012; 24: 247 - 254

109 van Assche G, Dignass A, Panes J et al. The second European evidencebased Consensus on the diagnosis and management of Crohn's disease: Definitions and diagnosis. J Crohns Colitis 2010; 4: 7-27

110 Jensen MD, Nathan T, Rafaelsen SR et al. Ileoscopy reduces the need for small bowel imaging in suspected Crohn's disease. Dan Med J 2012; 59: A4491

111 Samuel S, Bruining DH, Loftus EV et al. Endoscopic skipping of the distal terminal ileum in Crohn's disease can lead to negative results from ileocolonoscopy. Clin Gastroenterol Hepatol 2012; 10: 1253-1259

112 Koulaouzidis A, Rondonotti E, Karargyris A. Small-bowel capsule endoscopy: a ten-point contemporary review. World J Gastroenterol 2013; 19: $3726-3746$

113 Tukey M, Pleskow D, Legnani P et al. The utility of capsule endoscopy in patients with suspected Crohn's disease. Am J Gastroenterol 2009; 104: $2734-2739$

114 Mow WS, Lo SK, Targan SR et al. Initial experience with wireless capsule enteroscopy in the diagnosis and management of inflammatory bowel disease. Clin Gastroenterol Hepatol 2004; 2: 31 - 40

115 Leighton JA. The role of endoscopic imaging of the small bowel in clinical practice. Am J Gastroenterol 2011; 106: 27-36

116 Lewis BS, Eisen GM, Friedman S. A pooled analysis to evaluate results of capsule endoscopy trials. Endoscopy 2005; 37: 960 - 965

117 Bourreille A, Ignjatovic A, Aabakken L et al. Role of small-bowel endoscopy in the management of patients with inflammatory bowel disease: an international OMED-ECCO consensus. Endoscopy 2009; 41: $618-637$

118 Mehdizadeh S, Chen GC, Barkodar L et al. Capsule endoscopy in patients with Crohn's disease: diagnostic yield and safety. Gastrointest Endosc 2010; 71: $121-127$

119 Doherty GA, Moss AC, Cheifetz AS. Capsule endoscopy for small-bowel evaluation in Crohn's disease. Gastrointest Endosc 2011; 74: 167 175

120 Levesque BG. Yield to diagnostic accuracy: capsule endoscopy in Crohn's disease. Gastrointest Endosc 2010; 71: 128 - 130

121 Maiden L, Thjodleifsson B, Seigal A et al. Long-term effects of nonsteroidal anti-inflammatory drugs and cyclooxygenase- 2 selective agents on the small bowel: a cross-sectional capsule enteroscopy study. Clin Gastroenterol Hepatol 2007; 5: 1040 - 1045

122 Graham DY, Opekun AR, Willingham FF et al. Visible small-intestinal mucosal injury in chronic NSAID users. Clin Gastroenterol Hepatol 2005; $3: 55-59$

123 Goldstein JL, Eisen GM, Lewis B et al. Video capsule endoscopy to prospectively assess small bowel injury with celecoxib, naproxen plus omeprazole, and placebo. Clin Gastroenterol Hepatol 2005; 3: 133 141

124 Maiden $L$, Thjodleifsson B, Theodors $A$ et al. A quantitative analysis of NSAID-induced small bowel pathology by capsule enteroscopy. Gastroenterology 2005; 128: 1172 - 1178 
125 Lewis JR, Pashinsky Y, Tinsley A et al. Capsule endoscopy in healthy individuals. Gastroenterology 2012; 142 Suppl 1: S52-S53

126 Dionisio PM, Gurudu SR, Leighton JA et al. Capsule endoscopy has a significantly higher diagnostic yield in patients with suspected and established small-bowel Crohn's disease: a meta-analysis. Am J Gastroenterol 2010; 105: 1240-1248

127 Leighton JA, Gralnek IM, Cohen SA et al. Capsule endoscopy is superior to small-bowel follow-through and equivalent to ileocolonoscopy in suspected Crohn's disease. Clin Gastroenterol Hepatol 2014; 12: $609-615$

128 Jensen MD, Nathan T, Rafaelsen SR et al. Diagnostic accuracy of capsule endoscopy for small bowel Crohn's disease is superior to that of MR enterography or CT enterography. Clin Gastroenterol Hepatol 2011; 9: $124-129$

129 Toth E, Németh A, Nielsen J et al. Capsule endoscopy is superior to magnetic resonance enterography for detection of Crohn's lesions in the small bowel. Gut 2011; 60: A404

130 Pica R, Fouraki S, Cassieri C et al. Small bowel involvement in Crohn's disease: a prospective study comparing wireless capsule endoscopy and magnetic resonance enteroclysis. Gut 2012; 61: A398

131 Panes J, Bouhnik Y, Reinisch $W$ et al. Imaging techniques for assessment of inflammatory bowel disease: joint ECCO and ESGAR evidence-based consensus guidelines. J Crohns Colitis 2013; 7: 556-585

132 Lee SS, Kim AY, Yang SK et al. Crohn disease of the small bowel: comparison of CT enterography, MR enterography, and small-bowel follow-through as diagnostic techniques. Radiology 2009; 251: 751 761

133 Horsthuis K, Bipat S, Bennink RJ et al. Inflammatory bowel disease diagnosed with US, MR, scintigraphy, and CT: meta-analysis of prospective studies. Radiology 2008; 247: 64-79

134 Siddiki HA, Fidler JL, Fletcher JG et al. Prospective comparison of stateof-the-art MR enterography and CT enterography in small-bowel Crohn's disease. AJR Am J Roentgenol 2009; 193: 113-121

135 Fiorino G, Bonifacio C, Peyrin-Biroulet $L$ et al. Prospective comparison of computed tomography enterography and magnetic resonance enterography for assessment of disease activity and complications in ileocolonic Crohn's disease. Inflamm Bowel Dis 2011; 17: 1073 - 1080

136 Brenner DJ, Hall EJ. Computed tomography - an increasing source of radiation exposure. N Engl J Med 2007; 357: 2277 -2284

137 Freudenberg $L S$, Beyer $T$. Subjective perception of radiation risk. J Nucl Med 2011; 52: 29S - 35S

138 Solem CA, Loftus EVJr et al. Small-bowel imaging in Crohn's disease: a prospective, blinded, 4-way comparison trial. Gastrointest Endosc 2008; 68: 255-266

139 Cave D, Legnani P, de Franchis $R$ et al. ICCE consensus for capsule retention. Endoscopy 2005; 37: 1065-1067

140 Postgate AJ, Burling D, Gupta A et al. Safety, reliability and limitations of the given patency capsule in patients at risk of capsule retention: a 3-year technical review. Dig Dis Sci 2008; 53: 2732 -2738

141 Cheifetz AS, Kornbluth AA, Legnani P et al. The risk of retention of the capsule endoscope in patients with known or suspected Crohn's disease. Am J Gastroenterol 2006; 101: 2218-2222

142 Hoog CM, Bark LA, Arkani J et al. Capsule retentions and incomplete capsule endoscopy examinations: an analysis of 2300 examinations. Gastroenterol Res Pract 2012; 2012: 518718

143 Karagiannis S, Faiss S, Mavrogiannis C. Capsule retention: a feared complication of wireless capsule endoscopy. Scand J Gastroenterol 2009; 44: 1158 - 1165

144 Herrerias JM, Leighton JA, Costamagna $G$ et al. Agile patency system eliminates risk of capsule retention in patients with known intestinal strictures who undergo capsule endoscopy. Gastrointest Endosc 2008; 67: $902-909$

145 Yadav A, Heigh RI, Hara AK et al. Performance of the patency capsule compared with nonenteroclysis radiologic examinations in patients with known or suspected intestinal strictures. Gastrointest Endosc 2011; 74: 834-839

146 Handa 0 , Naito $Y$, Onozawa $Y$ et al. The usefulness of the self-dissolving patency capsule in the prediction of the intestinal stricture in patients with Crohn's disease: a prospective study. Gastrointest Endosc 2013; 77: AB172

147 May A, Manner H, Schneider M et al. Prospective multicenter trial of capsule endoscopy in patients with chronic abdominal pain, diarrhea and other signs and symptoms (CEDAP-Plus Study). Endoscopy 2007; 39: $606-612$
148 Bardan E, Nadler M, Chowers Y et al. Capsule endoscopy for the evaluation of patients with chronic abdominal pain. Endoscopy 2003; 35: $688-689$

149 Shim KN, Kim YS, Kim KJ et al. Abdominal pain accompanied by weight loss may increase the diagnostic yield of capsule endoscopy: a Korean multicenter study. Scand J Gastroenterol 2006; 41: 983-988

150 Adler SN, Yoav M, Eitan S et al. Does capsule endoscopy have an added value in patients with perianal disease and a negative work up for Crohn's disease? World J Gastrointest Endosc 2012; 4: 185 - 188

151 De Bona M, Bellumat A, Cian E et al. Capsule endoscopy findings in patients with suspected Crohn's disease and biochemical markers of inflammation. Dig Liver Dis 2006; 38: 331 - 335

152 Valle J, Alcantara M, Perez-Grueso MJ et al. Clinical features of patients with negative results from traditional diagnostic work-up and Crohn's disease findings from capsule endoscopy. J Clin Gastroenterol 2006; 40: $692-696$

153 Rosa B, Moreira MJ, Rebelo A et al. Lewis score: a useful clinical tool for patients with suspected Crohn's disease submitted to capsule endoscopy. J Crohns Colitis 2012; 6: 692 - 697

154 Rodrigues S, Magro F, Cardoso H et al. Role of capsule endoscopy in the evaluation of different segments of the small bowel in Crohn's disease: correlation of biomarkers, endoscopy, and Lewis score. Gastroenterology 2012; 142 Suppl 1: S787

155 Sipponen T, Haapamaki J, Savilahti E et al. Fecal calprotectin and S100A12 have low utility in prediction of small bowel Crohn's disease detected by wireless capsule endoscopy. Scand J Gastroenterol 2012; 47: $778-784$

156 Koulaouzidis A, Douglas S, Rogers MA et al. Fecal calprotectin: a selection tool for small bowel capsule endoscopy in suspected IBD with prior negative bi-directional endoscopy. Scand J Gastroenterol 2011; 46: $561-566$

157 Koulaouzidis A, Douglas S, Plevris JN. Lewis score correlates more closely with fecal calprotectin than Capsule Endoscopy Crohn's Disease Activity Index. Dig Dis Sci 2012; 57: 987-993

158 van Rheenen PF, Van de Vijver E, Fidler V. Faecal calprotectin for screening of patients with suspected inflammatory bowel disease: diagnostic meta-analysis. BMJ 2010; 341: c3369

159 Jensen MD, Kjeldsen J, Nathan T. Fecal calprotectin is equally sensitive in Crohn's disease affecting the small bowel and colon. Scand J Gastroenterol 2011; 46: 694-700

160 Hoog CM, Bark LA, Brostrom $O$ et al. Capsule endoscopic findings correlate with fecal calprotectin and C-reactive protein in patients with suspected small-bowel Crohn's disease. Scand J Gastroenterol 2014; 49: $1084-1090$

161 Lim YJ, Yang $\mathrm{CH}$. Non-steroidal anti-inflammatory drug-induced enteropathy. Clin Endosc 2012; 45: 138-144

162 Bjarnason I, Price AB, Zanelli $G$ et al. Clinicopathological features of nonsteroidal antiinflammatory drug-induced small intestinal strictures. Gastroenterology 1988; 94: 1070-1074

163 Maiden L. Capsule endoscopic diagnosis of nonsteroidal antiinflammatory drug-induced enteropathy. J Gastroenterol 2009; 44: 1964 71

164 Fujimori S, Gudis K, Takahashi Y et al. Distribution of small intestinal mucosal injuries as a result of NSAID administration. Eur J Clin Invest 2010; 40: 504-510

165 Matsumoto T, Kudo T, Esaki $M$ et al. Prevalence of non-steroidal antiinflammatory drug-induced enteropathy determined by double-balloon endoscopy: a Japanese multicenter study. Scand J Gastroenterol 2008; 43: 490-496

166 Leung WK, Bjarnason I, Wong VW et al. Small bowel enteropathy associated with chronic low-dose aspirin therapy. Lancet 2007; 369: 614

167 Higuchi K, Umegaki E, Watanabe T et al. Present status and strategy of NSAIDs-induced small bowel injury. J Gastroenterol 2009; 44: 879888

168 Voderholzer WA, Beinhoelzl J, Rogalla P et al. Small bowel involvement in Crohn's disease: a prospective comparison of wireless capsule endoscopy and computed tomography enteroclysis. Gut 2005; 54 : $369-373$

169 Petruzziello C, Onali S, Calabrese E et al. Wireless capsule endoscopy and proximal small bowel lesions in Crohn's disease. World J Gastroenterol 2010; 16: 3299-3304

170 Fork FT, Karlsson N, Kadhem $S$ et al. Small bowel enteroclysis with magnetic resonance imaging and computed tomography in patients with failed and uncertain passage of a patency capsule. BMC Med Imaging 2012; $12: 3$ 
171 Kalla R, McAlindon ME, Drew K et al. Clinical utility of capsule endoscopy in patients with Crohn's disease and inflammatory bowel disease unclassified. Eur J Gastroenterol Hepatol 2013; 25: 706 - 713

172 Long $M D$, Barnes $E$, Isaacs $K$ et al. Impact of capsule endoscopy on management of inflammatory bowel disease: a single tertiary care center experience. Inflamm Bowel Dis 2011; 17: 1855-1862

173 Lorenzo-Zuniga $V$, de Vega VM, Domenech $E$ et al. Impact of capsule endoscopy findings in the management of Crohn's disease. Dig Dis Sci 2010; 55: $411-414$

174 Flamant M, Trang C, Maillard $O$ et al. The prevalence and outcome of jejunal lesions visualized by small bowel capsule endoscopy in Crohn's disease. Inflamm Bowel Dis 2013; 19: 1390-1396

175 Dussault C, Gower-Rousseau C, Salleron J et al. Small bowel capsule endoscopy for management of Crohn's disease: a retrospective tertiary care centre experience. Dig Liver Dis 2013; 45: 558-561

176 van Tuyl SA, van Noorden JT, Stolk MF et al. Clinical consequences of videocapsule endoscopy in GI bleeding and Crohn's disease. Gastrointest Endosc 2007; 66: 1164-1170

177 Kopylov U, Nemeth A, Koulaouzidis A et al. Small bowel capsule endoscopy in the management of established Crohn's disease: clinical impact, safety, and correlation with inflammatory biomarkers. Inflamm Bowel Dis 2015; 21: $93-100$

178 Gralnek IM, Cohen SA, Ephrath $H$ et al. Small bowel capsule endoscopy impacts diagnosis and management of pediatric inflammatory bowel disease: a prospective study. Dig Dis Sci 2012; 57: 465 - 471

179 Rondonotti E, Soncini M, Girelli C et al. Small bowel capsule endoscopy in clinical practice: a multicenter 7-year survey. Eur J Gastroenterol Hepatol 2010; 22: 1380-1386

180 Esaki M, Matsumoto T, Watanabe K et al. Use of capsule endoscopy in patients with Crohn's disease in Japan: a multicenter survey. J Gastroenterol Hepatol 2014; 29: 96-101

181 Goel R, Hardman J, Gulati M et al. Video capsule retention in inflammatory bowel disease: an unusual presentation and discussion of retrieval methods. Case Rep Gastrointest Med 2013: article ID 607142

182 Cheon JH, Kim YS, Lee IS et al. Can we predict spontaneous capsule passage after retention? A nationwide study to evaluate the incidence and clinical outcomes of capsule retention Endoscopy 2007; 39: $1046-1052$

183 Despott EJ, Fraser C. Small bowel endoscopy in inflammatory bowel disease. Best Pract Res Clin Gastroenterol 2012; 26: 279-291

184 Pennazio M. Capsule endoscopy: where are we after 6 years of clinical use? Dig Liver Dis 2006; 38: 867-878

185 Viazis $N$, Zacharakis $G$, Saprikis $E$ et al. A single center experience of 2300 consecutive patients undergoing capsule endoscopy: indications and diagnostic yield. Endoscopy 2011; 43: A129

186 Gurudu SR, Leighton JA. Correlation of two capsule endoscopy scoring systems with fecal calprotectin: does it really matter? Dig Dis Sci 2012; 57: 827-829

187 Jensen MD, Nathan T, Kjeldsen J. Inter-observer agreement for detection of small bowel Crohn's disease with capsule endoscopy. Scand J Gastroenterol 2010; 45: 878-884

188 Gal E, Geller A, Fraser G et al. Assessment and validation of the new capsule endoscopy Crohn's disease activity index (CECDAI). Dig Dis Sci 2008; 53: $1933-1937$

189 Niv Y, Ilani S, Levi Z et al. Validation of the Capsule Endoscopy Crohn's Disease Activity Index (CECDAI or Niv score): a multicenter prospective study. Endoscopy 2012; 44: 21 - 26

190 Gralnek IM, de Franchis R, Seidman E et al. Development of a capsule endoscopy scoring index for small bowel mucosal inflammatory change. Aliment Pharmacol Ther 2008; 27: 146-154

191 Cotter J, Dias de Castro F, Magalhães J et al. Validation of the Lewis score for the evaluation of small-bowel Crohn's disease activity. Endoscopy $2015 \mathrm{Feb} 9$. Epub ahead of print

192 Swaminath A, Legnani P, Kornbluth A. Video capsule endoscopy in inflammatory bowel disease: past, present, and future redux. Inflamm Bowel Dis 2010; 16: 1254-1262

193 Efthymiou A, Viazis N, Mantzaris G et al. Does clinical response correlate with mucosal healing in patients with Crohn's disease of the small bowel? A prospective, case-series study using wireless capsule endoscopy Inflamm Bowel Dis 2008; 14: 1542 - 1547

194 Mann NK, Lo SK. Wireless capsule endoscopy improves outcomes in nonstricturing Crohn's disease: an evaluation of pre- and post-treatment capsule endoscopy (CE). Gastrointest Endosc 2013; 77: AB275
195 Hall B, Holleran G, Chin JL et al. A prospective 52 week mucosal healing assessment of small bowel Crohn's disease as detected by capsule endoscopy. J Crohns Colitis 2014; 8: 1601-1609

196 Daperno M, D'Haens G, van Assche G et al. Development and validation of a new, simplified endoscopic activity score for Crohn's disease: the SES-CD. Gastrointest Endosc 2004; 60: 505-512

197 Maunoury V, Savoye G, Bourreille A et al. Value of wireless capsule endoscopy in patients with indeterminate colitis (inflammatory bowel disease type unclassified). Inflamm Bowel Dis 2007; 13: 152 155

198 Mehdizadeh S, Chen G, Enayati PJ et al. Diagnostic yield of capsule endoscopy in ulcerative colitis and inflammatory bowel disease of unclassified type (IBDU). Endoscopy 2008; 40: 30-35

199 Di Nardo G, Oliva S, Ferrari $F$ et al. Usefulness of wireless capsule endoscopy in paediatric inflammatory bowel disease. Dig Liver Dis 2011; 43: 220-224

200 Joossens $S$, Reinisch $W$, Vermeire $S$ et al. The value of serologic markers in indeterminate colitis: a prospective follow-up study. Gastroenterology 2002; 122: 1242 - 1247

201 Henriksen M, Jahnsen J, Lygren I et al. Change of diagnosis during the first five years after onset of inflammatory bowel disease: results of a prospective follow-up study (the IBSEN Study). Scand J Gastroenterol 2006; 41: 1037-1043

202 Chevaux JB, Fiorino G, Frederic M et al. Capsule endoscopy in Crohn's disease. Curr Drug Targets 2012; 13: 1261 -1267

203 Condino G, Calabrese E, Onali $S$ et al. Small bowel capsule endoscopy for assessing early postoperative recurrence of Crohn's disease: a prospective longitudinal study. Gastroenterol 2013; 144 Suppl 1: S425

204 Pons Beltran V, Nos $P$ et al. Evaluation of postsurgical recurrence in Crohn's disease: a new indication for capsule endoscopy? Gastrointest Endosc 2007; 66: 533 - 540

205 Bourreille A, Jarry M, D'Halluin PN et al. Wireless capsule endoscopy versus ileocolonoscopy for the diagnosis of postoperative recurrence of Crohn's disease: a prospective study. Gut 2006; 55: 978 - 983

206 Buisson A, Chevaux JB, Bommelaer $G$ et al. Diagnosis, prevention and treatment of postoperative Crohn's disease recurrence. Dig Liver Dis 2012; 44: 453-460

207 Wiarda BM, Mensink PB, Heine DG et al. Small bowel Crohn's disease: MR enteroclysis and capsule endoscopy compared to balloon-assisted enteroscopy. Abdom Imaging 2012; 37: 397-403

208 Darbari A, Kalloo AN, Cuffari C. Diagnostic yield, safety, and efficacy of push enteroscopy in pediatrics. Gastrointest Endosc 2006; 64: $224-$ 228

209 Landi B, Tkoub M, Gaudric M et al. Diagnostic yield of push-type enteroscopy in relation to indication. Gut 1998; 42: $421-425$

210 Gay G, Delvaux M. Double balloon enteroscopy in Crohn's disease and related disorders: our experience. Gastrointest Endosc 2007; 66: S82-S90

211 Manes G, Imbesi V, Ardizzone S et al. Use of double-balloon enteroscopy in the management of patients with Crohn's disease: feasibility and diagnostic yield in a high-volume centre for inflammatory bowel disease. Surg Endosc 2009; 23: 2790 - 2795

212 Seiderer J, Herrmann K, Diepolder H et al. Double-balloon enteroscopy versus magnetic resonance enteroclysis in diagnosing suspected small-bowel Crohn's disease: results of a pilot study. Scand J Gastroenterol 2007; 42: 1376-1385

213 Sunada K, Yamamoto H, Kita H et al. Clinical outcomes of enteroscopy using the double-balloon method for strictures of the small intestine. World J Gastroenterol 2005; 11: 1087-1089

214 May A, Nachbar L, Ell C. Double-balloon enteroscopy (push-and-pull enteroscopy) of the small bowel: feasibility and diagnostic and therapeutic yield in patients with suspected small bowel disease. Gastrointest Endosc 2005; 62: 62 - 70

215 Prachayakul V, Deesomsak M, Aswakul P et al. The utility of single-balloon enteroscopy for the diagnosis and management of small bowel disorders according to their clinical manifestations: a retrospective review. BMC Gastroenterol 2013; 13: 103

216 Heine GD, Hadithi M, Groenen MJ et al. Double-balloon enteroscopy: indications, diagnostic yield, and complications in a series of $275 \mathrm{pa}-$ tients with suspected small-bowel disease. Endoscopy 2006; 38: 42 48

217 Mensink PB, Aktas H, Zelinkova Z et al. Impact of double-balloon enteroscopy findings on the management of Crohn's disease. Scand J Gastroenterol 2010; 45: 483-489 
218 Oshitani N, Yukawa T, Yamagami $H$ et al. Evaluation of deep small bowel involvement by double-balloon enteroscopy in Crohn's disease. Am J Gastroenterol 2006; 101: 1484-1489

219 de Ridder L, Mensink PB, Lequin MH et al. Single-balloon enteroscopy, magnetic resonance enterography, and abdominal US useful for evaluation of small-bowel disease in children with (suspected) Crohn's disease. Gastrointest Endosc 2012; 75: 87-94

220 Takenaka K, Ohtsuka K, Kitazume Y et al. Comparison of magnetic resonance and balloon enteroscopic examination of the small intestine in patients with Crohn's disease. Gastroenterology 2014; 147: 334342

221 Kondo J, Iijima H, Abe T et al. Roles of double-balloon endoscopy in the diagnosis and treatment of Crohn's disease: a multicenter experience. J Gastroenterol 2010; 45: 713-720

222 Xin L, Liao Z, Jiang YP et al. Indications, detectability, positive findings, total enteroscopy, and complications of diagnostic double-balloon endoscopy: a systematic review of data over the first decade of use. Gastrointest Endosc 2011; 74: 563-570

223 Lee BI, Choi H, Choi KY et al. Retrieval of a retained capsule endoscope by double-balloon enteroscopy. Gastrointest Endosc 2005; 62: $463-$ 465

224 Despott EJ, Gupta A, Burling D et al. Effective dilation of small-bowel strictures by double-balloon enteroscopy in patients with symptomatic Crohn's disease (with video). Gastrointest Endosc 2009; 70: $1030-1036$

225 Swaminath A, Lichtiger S. Dilation of colonic strictures by intralesional injection of infliximab in patients with Crohn's colitis. Inflamm Bowel Dis 2008; 14: 213-216

226 Di Nardo G, Oliva S, Passariello $M$ et al. Intralesional steroid injection after endoscopic balloon dilation in pediatric Crohn's disease with stricture: a prospective, randomized, double-blind, controlled trial. Gastrointest Endosc 2010; 72: 1201-1208

227 Fukumoto A, Tanaka S, Yamamoto $\mathrm{H}$ et al. Diagnosis and treatment of small-bowel stricture by double balloon endoscopy. Gastrointest Endosc 2007; 66 Suppl: S108-S112

228 Pohl J, May A, Nachbar $L$ et al. Diagnostic and therapeutic yield of push-and-pull enteroscopy for symptomatic small bowel Crohn's disease strictures. Eur J Gastroenterol Hepatol 2007; 19: 529-534

229 Hirai F, Верри T, Takatsu $N$ et al. Long-term outcome of endoscopic balloon dilation for small bowel strictures in patients with Crohn's disease. Dig Endosc 2014; 26: 545-551

230 Gill RS, Kaffes AJ. Small bowel stricture characterization and outcomes of dilatation by double-balloon enteroscopy: a single-centre experience. Therap Adv Gastroenterol 2014; 7: 108 - 114

231 Weinstein MC, Siegel JE, Gold MR et al. Recommendations of the Panel on Cost-effectiveness in Health and Medicine. JAMA 1996; 276: $1253-1258$

232 Gazelle GS, McMahon PM, Siebert $U$ et al. Cost-effectiveness analysis in the assessment of diagnostic imaging technologies. Radiology 2005; 235: $361-370$

233 Burisch J, Jess T, Martinato $M$ et al. The burden of inflammatory bowel disease in Europe. J Crohns Colitis 2013; 7: 322 - 337

234 Albert JG, Kotsch J, Kostler W et al. Course of Crohn's disease prior to establishment of the diagnosis. Z Gastroenterol 2008; 46: 187-192

235 Aggarwal V, Day AS, Connor SJ et al. Capsule endoscopy findings in small bowel Crohn's disease patients in clinical remission: correlation with the Crohn's disease activity index, faecal calprotectin and S100A12. Gastroenterology 2010; 138 Suppl 1: S114

236 Hoffmann JC, Preiss JC, Autschbach F et al. [Clinical practice guideline on diagnosis and treatment of Crohn's disease]. Z Gastroenterol 2008; 46: $1094-1146$

237 Rondonotti E, Soncini M, Girelli $C$ et al. Cost estimation of small bowel capsule endoscopy based on "real world" data: inpatient or outpatient procedure? Dig Liver Dis 2010; 42: 798 - 802

238 Tillack C, Seiderer J, Brand S et al. Correlation of magnetic resonance enteroclysis (MRE) and wireless capsule endoscopy (CE) in the diagnosis of small bowel lesions in Crohn's disease. Inflamm Bowel Dis 2008; $14: 1219-1228$

239 Ebinger M, Rieber A, Leidl R. Cost-effectiveness of magnetic resonance imaging and enteroclysis in the diagnostic imaging of Crohn's disease. Int J Technol Assess Health Care 2002; 18: 711-717

240 Cipriano LE, Levesque BG, Zaric GS et al. Cost-effectiveness of imaging strategies to reduce radiation-induced cancer risk in Crohn's disease. Inflamm Bowel Dis 2012; 18: 1240 - 1248
241 Albert JG, Nachtigall F, Wiedbrauck F et al. Minimizing procedural cost in diagnosing small bowel bleeding: comparison of a strategy based on initial capsule endoscopy versus initial double-balloon enteroscopy. Eur J Gastroenterol Hepatol 2010; 22: 679-688

242 Gerson L, Kamal A. Cost-effectiveness analysis of management strategies for obscure GI bleeding. Gastrointest Endosc 2008; 68: 920-936

243 Frilling A, Smith G, Clift AK et al. Capsule endoscopy to detect primary tumour site in metastatic neuroendocrine tumours. Dig Liver Dis 2014; 46: $1038-1042$

244 Johanssen S, Boivin $M$, Lochs $H$ et al. The yield of wireless capsule endoscopy in the detection of neuroendocrine tumors in comparison with CT enteroclysis. Gastrointest Endosc 2006; 63: 660-665

245 van Tuyl SA, van Noorden JT, Timmer R et al. Detection of small-bowel neuroendocrine tumors by video capsule endoscopy. Gastrointest Endosc 2006; 64: 66-72

246 Albert JG, Fechner M, Fiedler E et al. Algorithm for detection of smallbowel metastasis in malignant melanoma of the skin. Endoscopy 2011; 43: 490-498

247 Culliford A, Daly J, Diamond B et al. The value of wireless capsule endoscopy in patients with complicated celiac disease. Gastrointest Endosc 2005; 62: 55-61

248 Barret M, Malamut G, Rahmi G et al. Diagnostic yield of capsule endoscopy in refractory celiac disease. Am J Gastroenterol 2012; 107: $1546-1553$

249 Rondonotti E, Pennazio M, Toth E et al. Small-bowel neoplasms in patients undergoing video capsule endoscopy: a multicenter European study. Endoscopy 2008; 40: 488-495

250 Mitsui K, Tanaka S, Yamamoto H et al. Role of double-balloon endoscopy in the diagnosis of small-bowel tumors: the first Japanese multicenter study. Gastrointest Endosc 2009; 70: 498 - 504

251 Postgate A, Despott E, Burling D et al. Significant small-bowel lesions detected by alternative diagnostic modalities after negative capsule endoscopy. Gastrointest Endosc 2008; 68: 1209-1214

252 Hakim FA, Alexander JA, Huprich JE et al. CT-enterography may identify small bowel tumors not detected by capsule endoscopy: eight years experience at Mayo Clinic Rochester. Dig Dis Sci 2011; 56: 2914-2919

253 Nakatani M, Fujiwara Y, Nagami Y et al. The usefulness of double-balloon enteroscopy in gastrointestinal stromal tumors of the small bowel with obscure gastrointestinal bleeding. Intern Med 2012; 51: $2675-2682$

$254 \mathrm{He}$ Q Bai Y, Zhi FC et al. Double-balloon enteroscopy for mesenchymal tumors of small bowel: nine years' experience. World J Gastroenterol 2013; 19: 1820-1826

255 Cheung DY, Lee IS, Chang DK et al. Capsule endoscopy in small bowel tumors: a multicenter Korean study. J Gastroenterol Hepatol 2010; 25: $1079-1086$

256 Masselli G, Polettini E, Casciani E et al. Small-bowel neoplasms: prospective evaluation of MR enteroclysis. Radiology 2009; 251: $743-$ 750

257 Van Weyenberg SJ, Bouman K, Jacobs MA et al. Comparison of MR enteroclysis with video capsule endoscopy in the investigation of smallintestinal disease. Abdom Imaging 2013; 38: $42-51$

258 Saurin JC, Pilleul F, Soussan EB et al. Small-bowel capsule endoscopy diagnoses early and advanced neoplasms in asymptomatic patients with Lynch syndrome. Endoscopy 2010; 42: 1057-1062

259 Haanstra JF, Al-Toma A, Dekker E et al. Prevalence of small-bowel neoplasia in Lynch syndrome assessed by video capsule endoscopy. Gut 2014 Sep 10. DOI 10.1136/gutjnl-2014-307348. Epub ahead of print

260 Shyung LR, Lin SC, Shih SC et al. Proposed scoring system to determine small bowel mass lesions using capsule endoscopy. J Formos Med Assoc 2009; $108: 533-538$

261 Girelli CM, Porta P, Colombo E et al. Development of a novel index to discriminate bulge from mass on small-bowel capsule endoscopy. Gastrointest Endosc 2011; 74: 1067-1074

262 Bailey AA, Debinski HS, Appleyard MN et al. Diagnosis and outcome of small bowel tumors found by capsule endoscopy: a three-center Australian experience. Am J Gastroenterol 2006; 101: 2237-2243

263 Lee BI, Choi H, Choi KY et al. Clinical characteristics of small bowel tumors diagnosed by double-balloon endoscopy: KASID multi-center study. Dig Dis Sci 2011; 56: 2920-2927

264 Chen WG, Shan GD, Zhang $H$ et al. Double-balloon enteroscopy in small bowel tumors: a Chinese single-center study. World J Gastroenterol 2013; 19: $3665-3671$ 
265 Honda W, Ohmiya N, Hirooka Yet al. Enteroscopic and radiologic diagnoses, treatment, and prognoses of small-bowel tumors. Gastrointest Endosc 2012; 76: $344-354$

266 Nakamura M, Ohmiya N, Hirooka Y et al. Endoscopic diagnosis of follicular lymphoma with small-bowel involvement using video capsule endoscopy and double-balloon endoscopy: a case series. Endoscopy 2013; 45: 67-70

267 Albert JG, Schulbe R, Hahn L et al. Impact of capsule endoscopy on outcome in mid-intestinal bleeding: a multicentre cohort study in 285 patients. Eur J Gastroenterol Hepatol 2008; 20: 971 - 977

268 Saurin JC, Gutknecht C, Napoleon B et al. Surveillance of duodenal adenomas in familial adenomatous polyposis reveals high cumulative risk of advanced disease. J Clin Oncol 2004; 22: 493-498

269 Groves CJ, Saunders BP, Spigelman AD et al. Duodenal cancer in patients with familial adenomatous polyposis (FAP): results of a 10 year prospective study. Gut 2002; 50: 636-641

270 Koornstra JJ. Small bowel endoscopy in familial adenomatous polyposis and Lynch syndrome. Best Pract Res Clin Gastroenterol 2012; 26: $359-368$

271 Jagelman DG, DeCosse JJ, Bussey HJ. Upper gastrointestinal cancer in familial adenomatous polyposis. Lancet 1988; 1: 1149-1151

272 Burke CA, Santisi J, Church J et al. The utility of capsule endoscopy small bowel surveillance in patients with polyposis. Am J Gastroenterol 2005; 100: $1498-1502$

273 Schulmann K, Hollerbach S, Kraus K et al. Feasibility and diagnostic utility of video capsule endoscopy for the detection of small bowel polyps in patients with hereditary polyposis syndromes. Am J Gastroenterol 2005; 100: 27-37

274 Plum N, May A, Manner $H$ et al. Small-bowel diagnosis in patients with familial adenomatous polyposis: comparison of push enteroscopy, capsule endoscopy, ileoscopy, and enteroclysis. Z Gastroenterol 2009; 47: 339-346

275 Kong H, Kim YS, Hyun JJ et al. Limited ability of capsule endoscopy to detect normally positioned duodenal papilla. Gastrointest Endosc 2006; 64: $538-541$

276 Postgate A, Tekkis P, Fitzpatrick A et al. The impact of experience on polyp detection and sizing accuracy at capsule endoscopy: implications for training from an animal model study. Endoscopy 2008; 40: 496-501

277 Wong RF, Tuteja AK, Haslem DS et al. Video capsule endoscopy compared with standard endoscopy for the evaluation of small-bowel polyps in persons with familial adenomatous polyposis (with video). Gastrointest Endosc 2006; 64: 530-537

278 Caspari R, von Falkenhausen M, Krautmacher $C$ et al. Comparison of capsule endoscopy and magnetic resonance imaging for the detection of polyps of the small intestine in patients with familial adenomatous polyposis or with Peutz-Jeghers' syndrome. Endoscopy 2004; 36: $1054-1059$

279 Saurin JC, Ligneau B, Ponchon $T$ et al. The influence of mutation site and age on the severity of duodenal polyposis in patients with familial adenomatous polyposis. Gastrointest Endosc 2002; 55: 342-347

280 Ruys AT, Alderlieste YA, Gouma DJ et al. Jejunal cancer in patients with familial adenomatous polyposis. Clin Gastroenterol Hepatol 2010; 8: $731-733$

281 Lin OS, Brandabur JJ, Schembre DB et al. Acute symptomatic small bowel obstruction due to capsule impaction. Gastrointest Endosc 2007; 65: 725-728

282 Perez-Segura P, Siso I, Luque R et al. Iatrogenic intestinal obstruction: a rare complication of capsule endoscopy in a patient with familial adenomatous polyposis. Endoscopy 2007; 39 Suppl 1: E298 -E299

283 Matsumoto T, Esaki M, Yanaru-Fujisawa R et al. Small-intestinal involvement in familial adenomatous polyposis: evaluation by doubleballoon endoscopy and intraoperative enteroscopy. Gastrointest Endosc 2008; 68: 911-919

284 Alderlieste YA, Rauws EA, Mathus-Vliegen EM et al. Prospective enteroscopic evaluation of jejunal polyposis in patients with familial adenomatous polyposis and advanced duodenal polyposis. Fam Cancer 2013; $12: 51-56$

285 Monkemuller K, Fry LC, Ebert M et al. Feasibility of double-balloon enteroscopy-assisted chromoendoscopy of the small bowel in patients with familial adenomatous polyposis. Endoscopy 2007; 39: 52-57

286 Riccioni ME, Urgesi R, Cianci R et al. Single-balloon push-and-pull enteroscopy system: does it work? A single-center, 3-year experience Surg Endosc 2011; 25: 3050-3056
287 Gunther U, Bojarski C, Buhr HJ et al. Capsule endoscopy in small-bowe surveillance of patients with hereditary polyposis syndromes. Int J Colorectal Dis 2010; 25: 1377-1382

288 Langers AM, De Vos tot Nederveen Cappel WH, Veenendaal RA et al. Double balloon endoscopy for detection of small-bowel adenomas in familial adenomatous polyposis after pancreaticoduodenectomy according to Whipple. Endoscopy 2008; 40: 773-774

289 Korsse SE, Dewint P, Kuipers EJ et al. Small bowel endoscopy and Peutz-Jeghers syndrome. Best Pract Res Clin Gastroenterol 2012; 26: 263-278

290 Beggs AD, Latchford AR, Vasen HF et al. Peutz-Jeghers syndrome: a systematic review and recommendations for management. Gut 2010; 59: $975-986$

291 Brown G, Fraser C, Schofield G et al. Video capsule endoscopy in peutzjeghers syndrome: a blinded comparison with barium followthrough for detection of small-bowel polyps. Endoscopy 2006; 38: $385-390$

292 Mata A, Llach J, Castells A et al. A prospective trial comparing wireless capsule endoscopy and barium contrast series for small-bowel surveillance in hereditary GI polyposis syndromes. Gastrointest Endosc 2005; 61: 721 - 725

293 Postgate A, Hyer W, Phillips R et al. Feasibility of video capsule endoscopy in the management of children with Peutz-Jeghers syndrome: a blinded comparison with barium enterography for the detection of small bowel polyps. J Pediatr Gastroenterol Nutr 2009; 49: 417-423

294 Gupta A, Postgate AJ, Burling D et al. A prospective study of MR enterography versus capsule endoscopy for the surveillance of adult patients with Peutz-Jeghers syndrome. AJR Am J Roentgenol 2010 195: $108-116$

295 Urquhart P, Grimpen F, Lim GJ et al. Capsule endoscopy versus magnetic resonance enterography for the detection of small bowel polyps in Peutz-Jeghers syndrome. Fam Cancer 2014; 13: 249-255

296 Maccioni F, Al Ansari N, Mazzamurro F et al. Surveillance of patients affected by Peutz-Jeghers syndrome: diagnostic value of MR enterography in prone and supine position. Abdom Imaging 2012; 37: $279-287$

297 Soares J, Lopes L, Vilas BG et al. Wireless capsule endoscopy for evaluation of phenotypic expression of small-bowel polyps in patients with Peutz-Jeghers syndrome and in symptomatic first-degree relatives. Endoscopy 2004; 36: 1060-1066

298 Matsumoto T, Esaki M, Moriyama T et al. Comparison of capsule endoscopy and enteroscopy with the double-balloon method in patients with obscure bleeding and polyposis. Endoscopy 2005; 37: $827-832$

299 Rahmi G, Samaha E, Lorenceau-Savale C et al. Small bowel polypectomy by double balloon enteroscopy: Correlation with prior capsule endoscopy. World J Gastrointest Endosc 2013; 5: 219-225

300 Zhang W, Han ZL, Cheng Y et al. Value of the patency capsule in preevaluation for capsule endoscopy in cases of intestinal obstruction. J Dig Dis 2014; 15: 345-351

301 van Lier MG, Mathus-Vliegen EM, Wagner A et al. High cumulative risk of intussusception in patients with Peutz-Jeghers syndrome: time to update surveillance guidelines? Am J Gastroenterol 2011; 106: 940 945

302 van Lier MG, Wagner A, Mathus-Vliegen EM et al. High cancer risk in Peutz-Jeghers syndrome: a systematic review and surveillance recommendations. Am J Gastroenterol 2010; 105: 1258-1264

303 Pennazio M, Rossini FP. Small bowel polyps in Peutz-Jeghers syndrome: management by combined push enteroscopy and intraoperative enteroscopy. Gastrointest Endosc 2000; 51: 304-308

304 Gao H, van Lier MG, Poley JW et al. Endoscopic therapy of small-bowel polyps by double-balloon enteroscopy in patients with Peutz-Jeghers syndrome. Gastrointest Endosc 2010; 71: $768-773$

305 Ohmiya N, Nakamura M, Takenaka $\mathrm{H}$ et al. Management of smallbowel polyps in Peutz-Jeghers syndrome by using enteroclysis, double-balloon enteroscopy, and videocapsule endoscopy. Gastrointest Endosc 2010; 72: 1209-1216

306 Sakamoto H, Yamamoto H, Hayashi Y et al. Nonsurgical management of small-bowel polyps in Peutz-Jeghers syndrome with extensive polypectomy by using double-balloon endoscopy. Gastrointest Endosc 2011; 74: $328-333$

307 Urns AN, Martinello M, Rao P et al. Diagnostic and therapeutic utility of double-balloon enteroscopy in children. J Paediatr Gastroenterol Nutr 2014; 58: $204-212$ 
308 Torroni F, Romeo E, Rea $F$ et al. Conservative approach in Peutz-Jeghers syndrome: Single-balloon enteroscopy and small bowel polypectomy. World J Gastrointest Endosc 2014; 6: 318-323

309 Gastineau S, Viala J, Caldari D et al. Contribution of capsule endoscopy to Peutz-Jeghers syndrome management in children. Dig Liver Dis 2012; 44: 839-843

310 Mustalahti K, Catassi C, Reunanen A et al. The prevalence of celiac disease in Europe: results of a centralized, international mass screening project. Ann Med 2010; 42: 587-595

311 Ludvigsson JF, Rubio-Tapia A, van Dyke CT et al. Increasing incidence of celiac disease in a North American population. Am J Gastroenterol 2013; 108: 818-824

312 Jones HJ, Warner JT. NICE clinical guideline 86. Coeliac disease: recognition and assessment of coeliac disease. Arch Dis Child 2010; 95 : $312-313$

313 Hopper AD, Cross SS, Sanders DS. Patchy villous atrophy in adult patients with suspected gluten-sensitive enteropathy: is a multiple duodenal biopsy strategy appropriate? Endoscopy 2008; 40: 219224

314 Murray JA, Rubio-Tapia A, van Dyke CT et al. Mucosal atrophy in celiac disease: extent of involvement, correlation with clinical presentation, and response to treatment. Clin Gastroenterol Hepatol 2008; 6: 186193

315 Horoldt BS, McAlindon ME, Stephenson TJ et al. Making the diagnosis of coeliac disease: is there a role for push enteroscopy? Eur J Gastroenterol Hepatol 2004; 16: 1143-1146

316 Ravelli A, Bolognini S, Gambarotti M et al. Variability of histologic lesions in relation to biopsy site in gluten-sensitive enteropathy. Am J Gastroenterol 2005; 100: 177-185

317 Petroniene R, Dubcenco E, Baker JP et al. Given capsule endoscopy in celiac disease: evaluation of diagnostic accuracy and interobserver agreement. Am J Gastroenterol 2005; 100: 685-694

318 Hopper AD, Sidhu R, Hurlstone DP et al. Capsule endoscopy: an alternative to duodenal biopsy for the recognition of villous atrophy in coeliac disease? Dig Liver Dis 2007; 39: 140-145

319 Lidums I, Cummins AG, Teo E. The role of capsule endoscopy in suspected celiac disease patients with positive celiac serology. Dig Dis Sci 2011; 56: 499-505
320 Rondonotti E, Spada C, Cave D et al. Video capsule enteroscopy in the diagnosis of celiac disease: a multicenter study. Am J Gastroenterol 2007; 102: $1624-1631$

321 Adler SN, Jacob H, Lijovetzky G et al. Positive coeliac serology in irritable bowel syndrome patients with normal duodenal biopsies: Video capsule endoscopy findings and HLA-DQ typing may affect clinical management. J Gastrointest Liver Dis 2006; 15: 221 - 225

322 Kurien M, Evans KE, Aziz I et al. Capsule endoscopy in adult celiac disease: a potential role in equivocal cases of celiac disease? Gastrointest Endosc 2013; 77: 227-232

323 Tursi A. Endoscopic diagnosis of celiac disease: what is the role of capsule endoscopy? Gastrointest Endosc 2013; 78: 381

324 Daum S, Wahnschaffe U, Glasenapp R et al. Capsule endoscopy in refractory celiac disease. Endoscopy 2007; 39: 455-458

325 Atlas DS, Rubio-Tapia A, van Dyke CT et al. Capsule endoscopy in nonresponsive celiac disease. Gastrointest Endosc 2011; 74: 1315-1322

326 Joyce AM, Burns DL, Marcello PW et al. Capsule endoscopy findings in celiac disease associated enteropathy-type intestinal T-cell lymphoma. Endoscopy 2005; 37: 594-596

327 Mooney PD, Evans KE, Singh S et al. Treatment failure in coeliac disease: a practical guide to investigation and treatment of non-responsive and refractory coeliac disease. J Gastrointestin Liver Dis 2012; 21: $197-203$

328 Maiden L, Elliott T, McLaughlin SD et al. A blinded pilot comparison of capsule endoscopy and small bowel histology in unresponsive celiac disease. Dig Dis Sci 2009; 54: 1280-1283

329 Hadithi M, Al-toma A, Oudejans J et al. The value of double-balloon enteroscopy in patients with refractory celiac disease. Am J Gastroenterol 2007; 102: 987-996

330 Tomba C, Elli L, Bardella MT et al. Enteroscopy for the early detection of small bowel tumours in at-risk celiac patients. Dig Liver Dis 2014; 46: $400-404$

331 Van Weyenberg SJ, Meijerink MR, Jacobs MA et al. MR enteroclysis in refractory celiac disease: proposal and validation of a severity scoring system. Radiology 2011; 259: 151 -161

Appendices e1, e2 and e3

online content viewable at: www.thieme-connect.de 